\title{
Gleaning Non-trivial Structural, Functional and Evolutionary Information About Proteins by Iterative Database Searches
}

\section{Aravind ${ }^{1,2}$ and Eugene V. Koonin ${ }^{1 *}$}

${ }^{1}$ National Center for

Biotechnology Information

National Library of Medicine

National Institutes of Health

Bethesda, MD 20894, USA

${ }^{2}$ Department of Biology, Texas AEM University, College

Station, TX 77843, USA
Using a number of diverse protein families as test cases, we investigate the ability of the recently developed iterative sequence database search method, PSI-BLAST, to identify subtle relationships between proteins that originally have been deemed detectable only at the level of structure-structure comparison. We show that PSI-BLAST can detect many, though not all, of such relationships, but the success critically depends on the optimal choice of the query sequence used to initiate the search. Generally, there is a correlation between the diversity of the sequences detected in the first pass of database screening and the ability of a given query to detect subtle relationships in subsequent iterations. Accordingly, a thorough analysis of protein superfamilies at the sequence level is necessary in order to maximize the chances of gleaning non-trivial structural and functional inferences, as opposed to a single search, initiated, for example, with the sequence of a protein whose structure is available. This strategy is illustrated by several findings, each of which involves an unexpected structural prediction: (i) a number of previously undetected proteins with the HSP70-actin fold are identified, including a highly conserved and nearly ubiquitous family of metal-dependent proteases (typified by bacterial O-sialoglycoprotease) that represent an adaptation of this fold to a new type of enzymatic activity; (ii) we show that, contrary to the previous conclusions, ATP-dependent and NAD-dependent DNA ligases are confidently predicted to possess the same fold; (iii) the Cterminal domain of 3-phosphoglycerate dehydrogenase, which binds serine and is involved in allosteric regulation of the enzyme activity, is shown to typify a new superfamily of ligand-binding, regulatory domains found primarily in enzymes and regulators of amino acid and purine metabolism; (iv) the immunoglobulin-like DNA-binding domain previously identified in the structures of transcription factors NFKB and NFAT is shown to be a member of a distinct superfamily of intracellular and extracellular domains with the immunoglobulin fold; and (v) the Rag-2 subunit of the V-D-J recombinase is shown to contain a kelch-type $\beta$-propeller domain which rules out its evolutionary relationship with bacterial transposases.

Keywords: iterative database search; PSI-BLAST; structure prediction; DNA ligase; sialoglycoprotease

\section{Introduction}

Protein structure determination inevitably lags far behind the explosive quantitative and qualitative (thanks to the determination of genome sequences of taxonomicaly diverse organisms) growth of sequence databases. It has been observed, however, that newly determined structures increasingly tend to fall into already known
Abbreviations used: OSGP, O-sialoglycoprotease; MCE, mRNA capping enzyme; ACT, aspartokinase, chorismate mutase and TyrA; TIG, transcription factor IG; NR, non-redundant.

E-mail address of the corresponding author: koonin@ncbi.nlm.nih.gov 
structural folds (Murzin, 1996, 1998). This indicates that the number of folds (the basic types of globular domains) is finite and is unlikely to exceed a few thousand (Chothia, 1992; Orengo et al., 1994). Moreover, while it is difficult to estimate the total number of folds with a greater precision, it seems clear that for most of the widespread folds, representative structures are already available. Thus, it is highly probable that for any new protein sequence that does not have a significant compositional bias and, accordingly, is likely to form a globular domain(s) (Wootton, 1994), a structure with the same fold is present in the protein data bank (PDB; Bernstein et al., 1977). In order to obtain structural information about a given protein domain, all one needs is to establish a reliable alignment with the sequence of one of the domains with a known structure. More frequently than not, however, this task is not trivial. Major transitions in the evolution of life appear to have been accompanied (or in part driven) by the origin of new protein families from preexisting ones when sequences rapidly diverge, while the structure remains basically conserved (Doolittle, 1995). This erosion of sequence information in the course of evolution is the major obstacle in making structural predictions using homology inferred from sequence similarity. Accordingly, a number of unexpected connections between protein families originally thought to be unrelated have been recently established by comparison of experimentally determined three-dimensional structures (Holm \& Sander, 1996, 1997; Murzin, 1996, 1998; Murzin \& Bateman, 1997).

In order to maximize the rate of structural prediction from protein sequences, increasing sensitivity of sequence comparison methods is critical. The subtle relationships discovered by structurestructure comparison may be considered the golden standard for sequence analysis methods. Those methods that are sufficiently powerful to detect at least some of the connections originally perceived as "structural only" should be expected to routinely produce non-trivial structural predictions. Most of the advanced sequence database search methods utilize information contained in multiple alignments. The recently developed PSI (PositionSpecific Iterating)-BLAST method constructs a multiple alignment from the BLAST hits, converts it into a position-specific weight matrix and iterates the search using this matrix as the query (Altschul et al., 1997; Altschul \& Koonin, 1998). Several indepth studies of protein families as well as benchmarking experiments suggest that given the new level of protein sequence diversity coming from whole genome sequencing, this method may significantly increase our ability to detect subtle sequence similarities and, in particular, to make non-trivial structure predictions (Aravind \& Koonin, 1998; Aravind et al., 1998; Huyney et al., 1998; Mushegian et al., 1997; Rychlewski et al., 1998; Wolf et al., 1999).
Here, using several previously described cases of relationships between protein families that have been deemed to be detectable only by structurestructure comparison, we show that with appropriate starting points, PSI-BLAST is capable of detecting, at the sequence level, many of these subtle similarities. We demonstrate that typically, the best starting points for the iterative search are those that produce the greatest diversity of hits in the first BLAST pass. We then investigate several new examples of unexpected structural inferences for highly conserved protein domains that have important functional and evolutionary implications.

\section{Results and Discussion}

\section{The strategy for protein superfamily analysis using PSI-BLAST}

For assessing the ability of PSI-BLAST to detect subtle similarity between proteins, we chose several cases where a relationship originally has been discovered by structure-structure comparison and has been deemed undetectable at the sequence level (Table 1). The examples include the classical case of structural similarity between actins, the HSP70 class of molecular chaperones and sugar kinases (Bork et al., 1992), as well as more recently described relationships, such as those between antibiotic nucleotidyltransferases and DNA polymerase $\beta$ (Holm \& Sander, 1995; Aravind \& Koonin, 1999), ClpP protease and enoyl dehydratase (Murzin, 1998), and the nicking-rejoining domains of type I and type II DNA topoisomerases (Berger et al., 1998). A detailed examination of these examples showed that PSI-BLAST detects many, though not all, relationships originally thought to be tractable only at the structural level (Table 1).

This analysis also highlighted a major problem that must be taken into account in order to optimize the detection of protein superfamilies with iterative database search methods, such as PSIBLAST. The position-specific weight matrix in PSIBLAST is built using a single starting query sequence, and detailed analysis of the examples included in Table 1, as well as a number of other cases (L.A. and E.V.K., unpublished observations), indicates that the results dramatically depend on the choice of the query. In each investigated example, some queries were much more effective than others in the delineation of the respective superfamily by PSI-BLAST searches (Table 1). Furthermore, for certain superfamilies, particularly large ones such as the HSP70-actin-like enzymes and the nucleotidyltransferases, no single query could retrieve all members. Accordingly, the results produced with different queries had to be combined in order to fully characterize the respective superfamily. So far, there is no rigorous criterion to determine the effectiveness or quality of a query sequence. We noticed, however, an intui- 
Table 1. Detection of protein superfamilies using iterative database search (PSI-BLAST) and different queries

\begin{tabular}{|c|c|c|c|c|c|}
\hline $\begin{array}{l}\text { Protein or domain } \\
\text { superfamily defined by } \\
\text { structure comparison } \\
\text { (references) }\end{array}$ & $\begin{array}{l}\text { Representatives, including } \\
\text { proteins with known } \\
\text { structure and "structural } \\
\text { only" similarity to each }_{\text {other }^{\text {a }}}\end{array}$ & $\begin{array}{l}\text { Number of hits with } \\
e<0.01 \text { in first pass } \\
(e \text {-value of last hit) }\end{array}$ & $\begin{array}{l}\text { Number of iterations } \\
\text { for detection of } \\
\text { maximal } \\
\text { representative } \\
\text { diversity }\end{array}$ & $\begin{array}{l}\text { Number of clusters } \\
\text { formed by hits }\end{array}$ & $\begin{array}{l}\text { Diversity in terms of families within the superfamily } \\
\text { detected by the given query }\end{array}$ \\
\hline \multirow{3}{*}{$\begin{array}{l}\text { ClpP/enoyl dehydratase } \\
\text { (Murzin, 1998) }\end{array}$} & ClpP protease $^{\mathbf{b}}(116523)$ & $50\left(10^{-7}\right)$ & 3 & 2 & \multirow{3}{*}{$\begin{array}{l}\text { Four families: ClpP, protease IV, enoyl dehydratase, and } \\
\text { Acetyl coA carboxylase. All these families are detected } \\
\text { by each of the queries }\end{array}$} \\
\hline & $\begin{array}{l}\text { Enoyl-CoA dehydratase } \\
\text { (1dub) }\end{array}$ & $124(0.001)$ & 5 & 3 & \\
\hline & Protease IV (2826302) & $38\left(10^{-5}\right)$ & 2 & 4 & \\
\hline \multirow{3}{*}{$\begin{array}{l}\text { Toprim (catalytic domain of } \\
\text { topoisomerases and } \\
\text { primases) (Aravind et al., } \\
\text { 1998) }\end{array}$} & Topoisomerase IA (1ecl) & $43(0.007)$ & $\mathrm{C}^{\mathrm{c}}$ & 1 & \multirow{3}{*}{$\begin{array}{l}\text { Five families: topoisomerase IA, topoisomerase II, } \\
\text { primases, small primase-like proteins and Old family } \\
\text { nuclease. Representatives of all families are detected only } \\
\text { by BB0626 }\end{array}$} \\
\hline & Topoisomerase II (1bgw) & $198(0.004)$ & $\mathrm{C} 2$ & 1 & \\
\hline & $\begin{array}{l}\text { Small, primase-like protein } \\
\text { BB0626 from Borrelia } \\
\text { burgdorferi (2688557) }\end{array}$ & $6(0.004)$ & 4 & 2 & \\
\hline \multirow{3}{*}{$\begin{array}{l}\text { ATP Grasp (Galperin \& } \\
\text { Koonin, 1997) }\end{array}$} & Synapsin (1aux) & $29\left(10^{-41}\right)$ & $\mathrm{C} 1$ & 1 & \multirow{3}{*}{$\begin{array}{l}\text { ca Ten families. The DD ligase starting point detects all } \\
\text { families, for which sequence conservation could be } \\
\text { shown by detailed comparative analysis (Galperin \& } \\
\text { Koonin, 1997) }\end{array}$} \\
\hline & $\begin{array}{l}\text { D-alanine D-alanine ligase } \\
\text { (1iow) }\end{array}$ & $104(0.004)$ & 4 & 4 & \\
\hline & $\begin{array}{l}\text { Biotin carboxylase ( } 3328523) \\
\text { from Chlamydia trachomatis }\end{array}$ & $124(0.008)$ & $\begin{array}{l}6 \text { (does not recover all } \\
\text { families, eg synapsin) }\end{array}$ & 2 & \\
\hline \multirow{3}{*}{$\begin{array}{l}\text { Polß-type nucleotidyl } \\
\text { transferases (Holm \& } \\
\text { Sander, 1995; Aravind \& } \\
\text { Koonin, 1999) }\end{array}$} & Kanamycin nucleotidyl & $8\left(10^{-19}\right)$ & $\mathrm{C} 1$ & 1 & \multirow{3}{*}{$\begin{array}{l}\text { Nine families. None of the queries tried so far detects the } \\
\text { entire superfamily; this requires transitive searches with } \\
\text { several queries. YOL115w is the best query which } \\
\text { detects } 4 \text { families. }\end{array}$} \\
\hline & $\begin{array}{c}\text { transferase (1kan) } \\
\text { Polymerase } \beta \text { (1bpe) }\end{array}$ & $37(0.009)$ & $\mathrm{C} 2$ & 1 & \\
\hline & $\begin{array}{l}\text { Putative yeast nucleotidyl } \\
\text { transferase YOL115w } \\
\text { (1077298) (L.A. and E.V.K., } \\
\text { unpublished observations) }\end{array}$ & $15(0.005)$ & C6 & 2 & \\
\hline \multirow{3}{*}{$\begin{array}{l}\text { HSP70/actin domain } \\
\text { (duplicated RnaseH } \\
\text { module) (Bork et al., 1992; } \\
\text { Reizer et al., 1993; Koonin, } \\
\text { 1994; see also Figures } 1 \\
\text { and 2) }\end{array}$} & Hexokinase (1hkb) & $35(0.008)$ & $\mathrm{C} 3$ & 1. & \multirow{3}{*}{$\begin{array}{l}\text { At least } 12 \text { families all of which could not be detected by } \\
\text { any single query (see text). The best query is actin which } \\
\text { detected four families as opposed to two detected by } \\
\text { DnaK and one by hexokinase. }\end{array}$} \\
\hline & Actin (1atn) & $515\left(10^{-25}\right)$ & 6 & 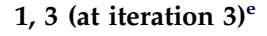 & \\
\hline & DnaK (1dkg) & $659\left(10^{-30}\right)$ & C5 & 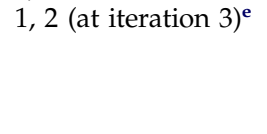 & \\
\hline \multirow{3}{*}{$\begin{array}{l}\text { Double-stranded } \beta \text {-helix } \\
\quad \text { (Gane et al., 1998) }\end{array}$} & Vicilin (1cax) & $83(0.006)$ & $\mathrm{C} 4$ & 3 & \multirow{3}{*}{$\begin{array}{l}\text { Several distinct families many of which have lost the } \\
\text { characteristic histidine residues (L.A., M. Y. Galperin and } \\
\text { E.V.K., unpublished observations). Representatives of all } \\
\text { these families are detected by CurC whereas AraC and } \\
\text { Vicilin at convergence detect only members of their own } \\
\text { families. }\end{array}$} \\
\hline & $\operatorname{AraC}(2 \mathrm{aac})$ & $8\left(10^{-43}\right)$ & $\mathrm{C} 1$ & 1 & \\
\hline & CurC(729227) & $16(0.008)$ & 4 & 6 & \\
\hline
\end{tabular}

a The PDB code (whenever available) or the Gene Identification number in the NR database is indicated in parentheses; the best query is shown by bold type.
b The structure of ClpP was used for this comparison (Murzin, 1998), although it is not yet in PDB.

c $\mathrm{Cn}$ indicates convergence after $n$ iterations

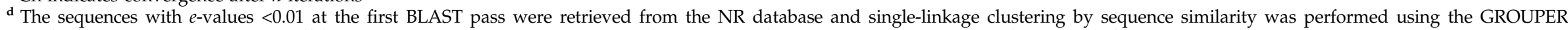
script of the SEALS package (the cut-off for clustering was adjusted individually for each superfamily and was in the range of 0.5-0.75 bit/position)

$\mathrm{e}$ In these searches, the diversity of the hits appears only in the third iteration. 
tively plausible, positive correlation between the diversity among the sequences retrieved in the first pass (or less frequently in a subsequent iteration) and the success in retrieval of the superfamily members by a given query in the iterative search. In each of the examples, the sequences whose hits formed the greatest number of distinct clusters fared best in terms of the recovery of the entire superfamily using PSI-BLAST (Table 1). Thus it appears that the optimal strategy for protein superfamily analysis using PSI-BLAST should include either an exhaustive iterative search using all known members or, particularly in the case of large superfamilies, the selection of a set of queries that are likely to perform well on the basis of the diversity criterion.

It should be emphasized that the problem of choosing the optimal query for iterative database searching is completely different from the wellknown problem of weighting sequences prior to position-dependent matrix construction. When the query used for a search is a member of a large family within a protein superfamily, weighting is critical in order to avoid skewing the matrix towards this particular family (Vingron \& Sibbald, 1993). A simple but apparently effective weighting procedure is incorporated in the PSI-BLAST program (Altschul et al., 1997; Henikoff \& Henikoff, 1994). However, the only thing any weighting scheme can do is reducing the bias in the data; it cannot increase the ultimate diversity of the data that seems to determine, at least in part, the searching power of the constructed matrix (Table 1).

The issue of the choice of the optimal query(s) is particularly relevant when structure prediction using iterative database search with PSI-BLAST is considered. Indeed, the observations discussed above make it clear that starting the search with the sequence of a protein whose structure is available is not necessarily the best way to detect subtle structural relationships. Nor is it sufficient to start the search with the sequence of a structurally uncharacterized protein and look for similarity to a sequence from the PDB. This is exemplified by the case of synapsin whose relationship to the ATPgrasp enzyme superfamily was originally detected by structure comparison (Esser et al., 1998). A search initiated with the synapsin sequence does not detect any non-trivial relationships. In contrast, several sequences of ATP-grasp proteins readily retrieve the synapsin sequence from the NR database at a statistically highly significant level (Table 1).

Thus the use of optimal starting points, at least in some case, has the potential to significantly increase the chance of revealing relationships between structurally uncharacterized protein families and known structures represented in the PDB. Below we describe the application of this strategy to several biologically interesting protein superfamilies; these examples further illustrate the potential of the iterative sequence search in detecting non-trivial relationships between proteins and the importance of the optimal selection of starting points.

\section{Non-trivial structural inferences from iterative sequence database searches}

\section{New families within the HSP70-actin fold}

This fold includes a number of ATP-dependent enzymes, some of which possess molecular chaperone and other additional activities, such as the nearly ubiquitous chaperone Hsp70, the eukaryotic cytoskeletal protein actin, sugar kinases, phosphatases (e.g. Escherichia coli Ppx) and proteins whose exact activities are not known, e.g. bacterial cell cycle proteins MreB and FtsA (Bork et al., 1992; Reizer et al., 1993; Koonin, 1994). Our analysis using selected starting points identified a number of new proteins that are predicted to possess the HSP70-actin fold, some of which are highly conserved in taxonomically diverse species (Table 1 and Figure 1). The most notable of these are the O-sialoglycoproteases (OSGPs). This protein family is represented in all organisms whose genomes have been sequenced so far, and the E. coli and Bacillus subtilis OSGPs are essential for bacterial growth (Arigoni et al., 1998). OSGPs possess metaldependent protease activity (Abdullah et al., 1992; Mellors \& Lo, 1995). Consistent with this, they contain a highly conserved histidine residue dyad which is typical of metal coordination sites of other metal-dependent proteases. A PSI-BLAST search started with most of the OSGP sequences converged after retrieving the members of this family. In contrast, a search started with the protein AF1959 (gi:2648583, Figure 1), the predicted $R$-hydroxyglutaryl-CoA dehydratase activator from the archaeon Archaeoglobus fulgidus, retrieved the first representative of the OSGP family in the second iteration with an $e$-value of $2 \times 10^{-6}$ and most of the known and several new (see below) protein families that possess the HSP70/DnaK fold in subsequent iterations; this search did not produce any obvious false positives. An additional test using the ZEGA method predicted that OSGP and DnaK have the same fold with a $p$-value of $\sim 10^{-4}$. A multiple alignment analysis using the Gibbs sampling procedure indicated that OSGPs and HSP70 share several conserved motifs with associated probability of chance occurrence in the range of $\sim 10^{-6}$ to $10^{-20}$ (Figure 1). Mapping of these motifs onto the three-dimensional structure of HSP70 shows that they correspond to highly conserved structural elements of the HSP70/DnaK fold. The basic scaffold of the domain consists of two structurally similar halves which, in the SCOP database, are classified under the "RNaseH-like fold" (Hubbard et al., 1999). The ATP molecule is sandwiched between these symmetrically placed halves; this interaction involves two conserved loops flanked on either side by long $\beta$-strands. Both these loops and the strands of the ATP 
Secondary Structure:

OSGP_Af_2649475

OSGP EC 76240

OSGP_BS_1945110

OSGP_SC_1431146

NolO Ssp_1653353

Nolo Rhi 2182422

NodU Rhi 152116

HypF Mj 1591430

hypF_Rhi_420902

AF1959 Af 2648583

MJ0800_Mj_2127709

MJ0004_Mj_2127708

YjiL_Ec_1361068

aq_278.r1_Aae_2982990

aq 278.r2 Aae 2982990

BCRSub_Rp_2190581

HYD_PS_417168

HYD_Aae_2983296

HYD_Mj_2129140

P $\mathrm{Rr} 1732065$

YKV5 Sc 549754

UDPase_Hs_3153211

UDPase Sc 731435

CD39_Mm_2499219

GDPASE_Sc_418404

NTPA_PV_1709358

NTP1 Tq 2499220

GK_Zm_155593

GPPA EC 121561

HSP70_Tbru_320901

HSP 70R Sc 626174

1DKG_EC_239228

consensus/85\%
EEEEEEEE , EEEEE , EEEE .

IALGIFGTAWSLSI-GVVDEB

RVIGIETSCDETTI - AIYDDE

YVIGIETSCDI

YVLGIETSCDETAA-AIVKNCK

33 KVLAIETSCDDTCV-SVLDRFS

HILGISAYYHDSAA-ALVKDGV

GLSKIHE-NSLDLP

RICGIKLTHDGAIA-VVEDGRR

409 LCVGAELNSTACIV--KRDKF

402 IATGADLKNTICVT-RGREAFL

IAAGIII IGSLTĀKCALMRDGKI

ISLGIDSGSTTTKAVVMIDDEV

MILGIDVGSTTTKMVLMEDSK I

4 YSIGIDSGSTATKGI LLADGVI

20 VYIGVDGGSTSTKGVLLNEEGE

1 LTVGLDVGSTTVKA-VVIDENK

2 TFVGIDLGSTTTKA-VLMDENK

1 KLFGVDVGGTFTDI-IFSDTET VYVGVDTGGTFTDF - VYWDGKE

4 YRVGIDIGGTFTDL-VYFDEYS

7 FHFAIDRGGTFTDV-FAOCPGG

5 IRIAIDKGGTFTDC--VGNIGT

89 YGIVVDCGSSGSRV-FVYCWPR

9 FGIVIDAGSSGSRI - HVFKWOD

48 YGIVLDAGSSHTNL-YIYKWPA

92 YVIMIDAGSTGSRV-HIYKFDV

92 YAVVFDAGSTGSRI-HVYHFNQ

64 ALVVIDAGSSSTRT - NVFLAKT

1 EIVAIDIGGTHARF-SIAEVSN

6 LYAAIDLGSNSFHMLVVREVAG

37 PVIGITEGNTSSSI-AYINPKN

4 GAIGIDLGTTYSCV-GVWONER

2 KIIGIDLGTTNSCV-AIMDGTT

.hul-.sss.s.h.h.p. .

Phosphate

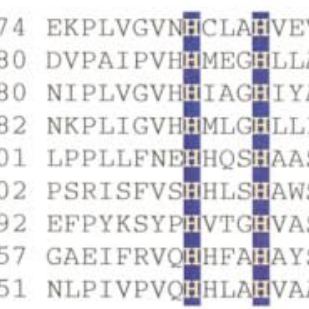

Zn-binding motif 109 DIGGASTELVTG 53 HGWKVCVGASGTVQALOEIMMA 14 LKORAIHCGRLE 245 173 DFGGIRSDAAVI 120 IDAVLLTGGVSFTPKLTTNLEY 18 NPNELAASGAAL 157 175 DFGGGTFDVSII 122 IEDVVLVGGSSRIPAVQAQLRE 11 HPDEAVAYGAAW 297 170 DLGGGTFISII 128 IDDVILVGGQTRMPMVQKKVAE 10 NPDEAVAIGAAV $6 /$

$$
\begin{array}{rr}
\text { huG ...ph... } & \text {..h.h.h huss... } \\
\text { phosphate II } & \text { Adenosine }
\end{array}
$$

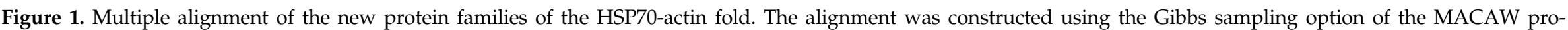

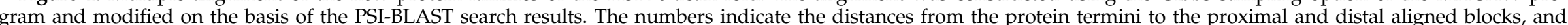

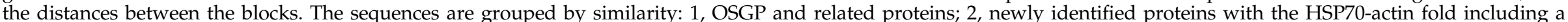

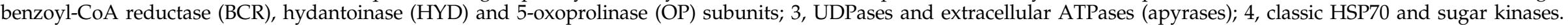

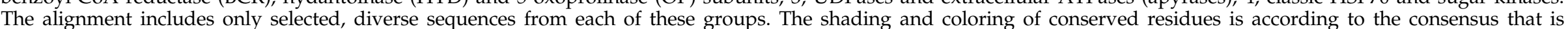

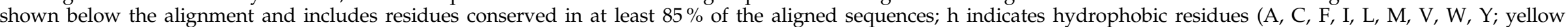

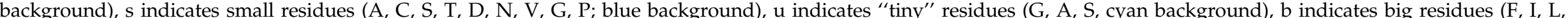

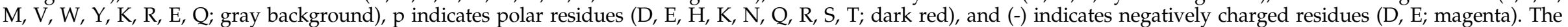

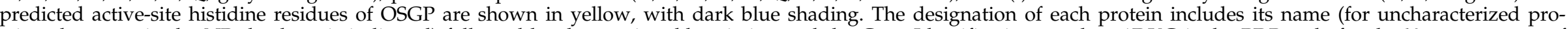

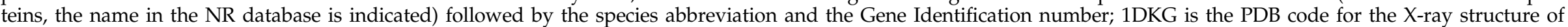

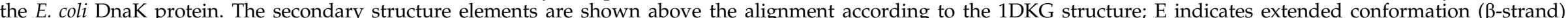

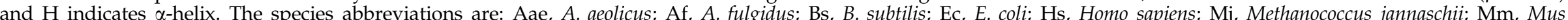

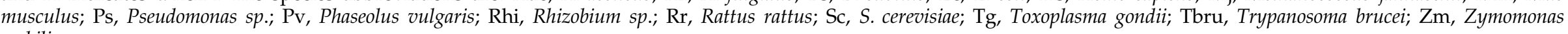
mobilis. 


\section{OSGP model}

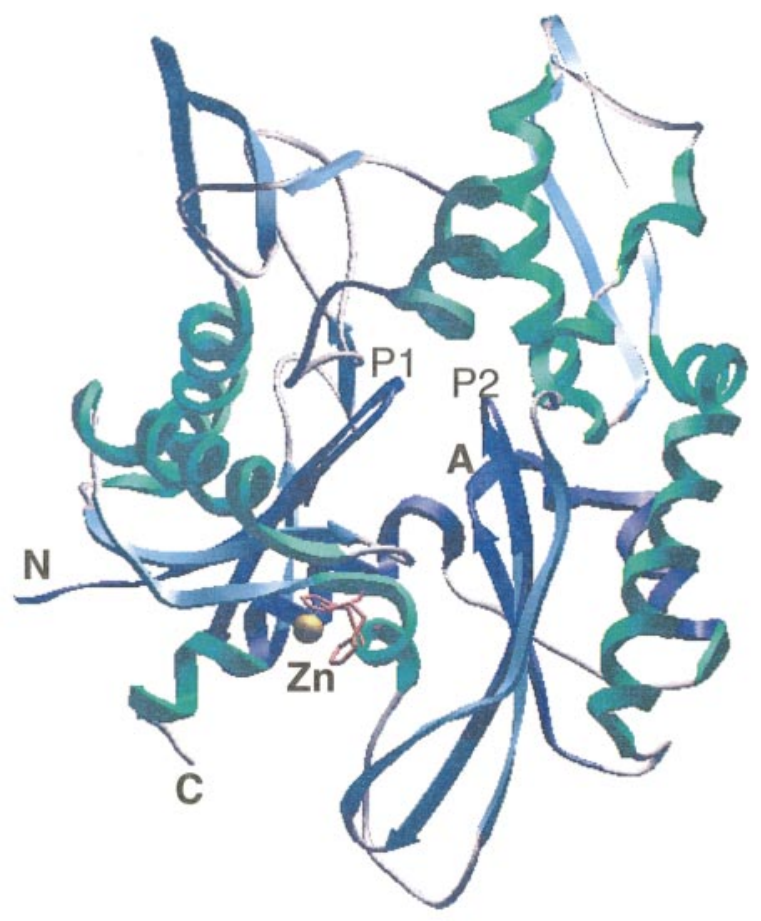

HSP70(1DKG)

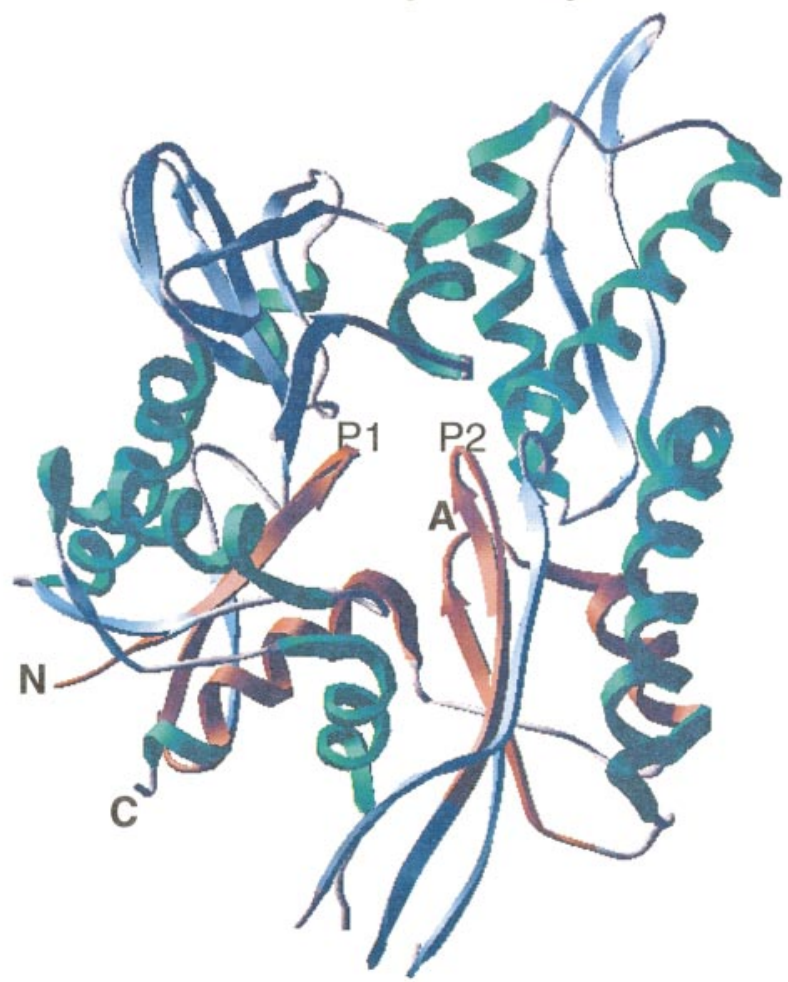

Figure 2. Comparison of the HSP70 structure and a structural model of the O-sialoglycoprotease. The conserved motifs from the alignment in Figure 1 are shown by dark red coloring in the 1DKG structure and by dark magenta coloring in the OSGP model. P1, P2 and A indicate the two phosphate binding site and the adenosine binding site, respectively. In the OSGP model, a $\mathrm{Zn}$ atom and two chelating histidine residues are shown.

binding site are conserved in the OSGPs (Figures 1 and 2).

Even a crude model of the OSGP structure generated using the HSP70 structures (1dkg and 1ngc) as templates provides some insight into the possible interaction between the active site of the protease and the ATPase domain. The predicted metal-chelating histidine residue dyad of the protease is located in a helical region which belongs to the linker between the two RNaseH-like halves of the molecule (Figure 2). This part of the molecule has a deep cleft that is predicted to accommodate both the metal atom and the peptide substrate; the protease active site is distinct from the ATP-binding cleft and points away from it (Figure 2). This represents a remarkable adaptation of the HSP70actin fold to the protease function by grafting a metal-binding motif onto its structural framework. It appears that this motif has evolved by mutation rather than by insertion and, accordingly, the similarity between the active sites of OSGPs and other metal-dependent proteases is purely convergent. These findings suggest that OSGP is an as yet uncharacterized ATP-dependent protease. The conservation of the two phosphate and adenosine binding sites (Figures 1 and 2) suggests that OSGP binds ATP similarly to the HSP70/DnaK fold pro- teins, which may result in a conformational change that could affect the protease active site. The protein-protein interaction domain of the HSP70/ DnaK-class molecular chaperones is located in the C-terminal region of these proteins (Martin \& Hartl, 1997) that is not conserved in OSGPs; therefore the prediction of the HSP70 fold may not directly indicate a chaperone function for OSGP. Nevertheless, the obvious analogy to other ATPdependent proteases, such as the Clp system, Lon and FtsH in bacteria (Gottesman, 1996; Gottesman \& Maurizi, 1992), suggests that like these proteases, OSGP may possess a chaperone-type activity. The nearly universal conservation of OSGP and its essential role in bacteria indicate that it has a critical cellular function, perhaps in the ATP-dependent degradation of some classes of misfolded proteins, that remains to be identified experimentally.

The Hsp70-actin superfamily domain of the OSGP-type, with the conserved histidine residue dyad, also occurs in multidomain bacterial and archaeal proteins, such as $\mathrm{HypF}$ and $\mathrm{NolO}$ (Figure 1). In HypF, the OSGP domain is combined with the small acyl phosphatase domain, $\mathrm{Zn}$ fingers and an uncharacterized, conserved "SUA5" domain, suggesting that this protein has multiple 
activities. As HypF participates in the biogenesis of the hydrogenase complex, which involves proteolytic steps (Colbeau et al., 1998), it seems likely that the OSGP domain contributes to this process both directly as a protease and as a chaperone. The NolO and NodU proteins are carbamoyl transferases (Jabbouri et al., 1998), and their predicted ATP-binding domain may participate in the formation of carbamoyl phosphate, though the role of the predicted protease activity remains unclear.

In addition to OSGP, iterative database searches started with the HSP70-actin fold protein sequences detected significant relationships with the subunits of hydantoinases (Watabe et al., 1992), oxo-prolinases (Ye et al., 1996) and benzoyl-CoA reductases (Gibson et al., 1997). In each of these cases, all the diagnostic motifs and residues typical of the HSP70 domain were conserved, and the respective proteins are predicted to be active ATPases (Figure 1). ATP dependence has been observed for the oxo-prolinases and certain hydantoinases (Ye et al., 1996), which suggests that the HSP70-like domain is indeed the domain involved in ATP utilization by these enzymes. In the case of the benzoyl-CoA reductases, at least one biochemically characterized, purified enzyme shows the requirement of ATP for conformational changes that are involved in its conversion into an active form; furthermore, in the absence of the aromatic substrate, the enzyme behaves as an ATPase (Boll \& Fuchs, 1995). This suggests a specific chaperonelike role for the HSP70 fold subunit of this enzyme. Generally, the identification of HSP70-actin fold in subunits of enzymes with diverse activities (Figure 1) seems to indicate that these proteins may be adapted for the previously under-appreciated role of activators/chaperones for specific enzyme systems.

An unusual relationship was observed between the HSP70-actin superfamily and eukaryotic UDPases (Wang \& Guidotti, 1998) and secreted NTPases (apyrases), such as CD39 (Komoszynski $\&$ Wojtczak, 1996). These sequences were retrieved in the PSI-BLAST searches and showed striking conservation of the N-terminal phosphate-binding motif of the HSP70 superfamily (Figure 1). The distal parts of these proteins, however, are highly divergent and the counterparts of the motifs that are conserved in the second RNaseH-like lobe of HSP70, in particular the adenosine-binding motif, could not be identified in the apyrases (Figure 1). This may reflect the fact that these enzymes are general nucleotide phosphatases that do not specifically recognize adenosine, and their C-terminal domain has diverged accordingly.

Thus iterative database searches using PSIBLAST with optimal starting points significantly expanded the HSP70-actin fold superfamily, and showed that this ancient ATPase domain has diversified and adapted in the course of evolution to perform a greater variety of functions than previously suspected.

\section{Unification of ATP-dependent and NAD-dependent $D N A$ ligases}

DNA ligases are among the central enzymes of DNA replication and repair. Previous sequence comparisons, as well as structural and functional studies, have led to the conclusion that the ATPdependent DNA ligases that are seen predominantly in eukaryotes, archaea, some viruses, and only sporadically in bacteria, were unrelated to the NAD-dependent ligases that are ubiquitous in bacteria (Shuman \& Schwer, 1995). In contrast, it has been demonstrated that ATP-dependent ligases share several conserved sequence motifs with the mRNA capping enzymes (MCEs) and RNA ligases (Shuman \& Schwer, 1995). The latter enzymes are confidently predicted to possess the same fold as the ATP-dependent ligases whose structure has been recently determined (Shuman, 1996; Subramanya et al., 1996). Using PSI-BLAST searches, we demonstrated a statistically significant relationship between the NAD-dependent and ATP-dependent ligases. For example, a search using the A.fulgidus ATP-dependent ligase I sequence as the query recovered the E. coli NADdependent ligase in the 5th iteration with an $e$-value of $10^{-4}$. Examination of the multiple alignment of the ligases constructed using the GIBBS sampling procedure showed that all the conserved elements which had unified the ATP-dependent ligases and the capping enzymes are detectable in the NAD-dependent ligases (Figure 3), with the probability of these motifs being detected by chance in the range of $10^{-5}$ to $10^{-20}$.

Mapping of the conserved motifs onto the ATPdependent ligase and MCE structures shows that both subdomains of the pincer-like structure of the ligases (classified as a version of the "ATP-grasp" fold in the SCOP database) are present in the NAD-dependent ligase (data not shown). The ATP molecule is bound at the interface of the two subdomains, and the conservation of both subdomains suggests that NAD is bound in essentially the same fashion. The strongest sequence conservation was seen in the elements corresponding to the active site and the $\beta$-strands that form the scaffold of the ligase domain. The lysine residue that covalently binds AMP at the intermediate step of the ligase reaction is bounded by two hydrophobic $\beta$-strands, and this arrangement is clearly conserved in both types of ligases (Figure 3). Two highly conserved acidic residues in motifs 2 and 4 that are probably necessary for the catalytic mechanism of the ATP-dependent ligases are also seen in the NAD-dependent ligases (Figure 3). The similarity of the motifs around the catalytic lysine residue in the ATP-dependent and NAD-dependent ligases has been noticed previously, but given the purported absence of other conserved features it has been attributed to convergence (Shuman \& Schwer, 1995). The detection of five conserved motifs and the overall similarity that suggests a common fold indicates that two types of ligases 
Secondary structure

DNLI_BPT7_118772

DNLIATP Aae 2983805

DNLI_SC_2506361

DNLI_VAC_118775

DNL4_Hs_1706482

DNLI1_Af 2649996

DNALI2_Af_2648829

MTCY22D7.19C_Mtu_1781151

aq_1106_Aae_2983583

AF0849_Af 2649752

YKP3_K1_140970

Y10A_T4_418318

L3169-5_Lm_2429116

VH65_NPV_73 1118

MCE1_Sp_729998

MCE_HS_2697129

MCE_ASFV_417283

1 CKN_PBCV 2392236

DNLJ_EC_2506362

DNLJ_Aae_2983242

DNLJ_Mge_1352291

YiCF_EC_401583

RNLI_T4_68670

TRNL SC 136250

consensus $/ 80 \%$
EEEEEE ....EEEEEEEE. 27 YLIAETKYDGVRNICVDN 180 KCGAEY YDGERIOAHRKG 292 TFTSEYKYDGERAQVHKGD 180 GMFAEVKYDGERVOVHKNNN 180 SFYIETKLDGERMQMHKDGD 180 TAAVEWKFDGSRVOVHWDGS 22 DHIYEVKWDGTRCLAFVDVE 180 TTIFEAKLDGARVQIHRAND

70 PFWVEEKVDGYNTRIFKYGD

89 EVVLEEKMNGYNVRIVKVGD

. EEEEEEEEEEE EEEEEEEEEHнHнНH

EEEEEE . . . . . KDGFMLDGELMVK 47 HIKLYAILPLHIVESGED 50 AEGHEGLIVKDP 10 GWWKMKPENEAD 113 7 PHDFIVELEAVVI 31 AGFLFDIIYL--DGEDLT 43 EEGCEGLVCKSL 13 LWIKYKRDYKSV 154 1 TKNLILDCEAVAW 30 CLFAFDILCY--NDERLI 44 NHSCEGLMVKML 14 NWLKLKKDYLEG 151 ATSIVLDSEIVLV 25 CLFVFDCLYF--DGFDMT 44 TRKLFGLVLKDI 9 RWLKIKRDYLNE 147 6 IQICILDGEMMAY 27 CYCVFDVLMV--NNKKLG 44 DKREFGIMVKOP 11 GWLKIKPEYVSG 454 7 KPGVILDGEVIAV 30 EAHFFDILYH--DGECID 42 SAGHEGVMIKLP 11 NWLKVKAIMETL 130

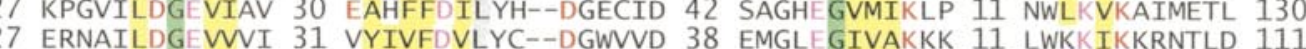
27 ERNAILDGEWVI 31 VYIVFDVLYC--DGWVVD 38 EMGLEGIVAKKK 11 LWKKIKKRNTLD 111

NPDLVICAEVAGP 16 QLFVFDFMKK--NEQGFL 41 EEGREGVVFKED 4 KRAKYITSYANL 133 ।

28 QWCISPKADGIHVLVYSDGE 17 KVNRIFEGELMSN 1 EILYFDCLMW--ENKNIT 36 DFETDGYIITNI 4 KVYKSKFKNTVD 258 I 18 EWVAREKIHGTNFSLIIERD 42 VVSYQVFGEFAGP 11 DFVFDIIVTTESGDVTY 67 VFTAEGYVLKPC 10 VAIKCKNSKFSE 101 | 3

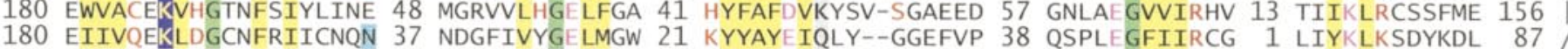

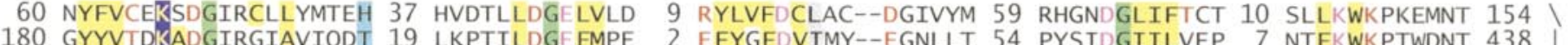
180 GYYVTDKADGIRGIAVIQDT 19 LKPTILDGEFMPE 2 EFYGFDVIMY--EGNLLT 54 PYSIDGIILVEP 7 NTFKWKPTWDNT 438 |

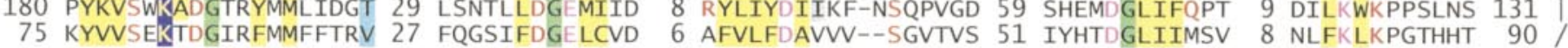
108 TWCCELKLDGLAVSILYENG 36 PARLEVRGEVFLP 43 TFFCYGVGVL--EGGELP 43 GFDIDGVVIKVN 18 VAFKFPAQEQMT 349 135 EYAVEPKLDGAGIALVYEND 37 IKLAEIRGEVVIR 43 EAIVYHLSYV--EPPETE 45 PYEIDGMVVKVN 18 IAYKFKPRRAVT 368 | 5 106 EFVVEPKIDGVSISLTYKNG 33 TKTIEIRGEIFVD 39 RALFYYIPNGL-EESITT 42 TFNLDGLVIKLN 18 IAFKFSPKFVQT 347 117 DLWVQPKVDGVAVTLVYRDG 34 LANSTLQGEIFLQ 31 GVFVWAWPDGP-QLMSDR 36 PFVTDGVVVRAA 16 VAWKYQPVAQVA 248

92 VDYILTKEDGSLVSTYLDGD 30 RDRLKELAEDGFT 32 EYISYDDIYKDATLRPYL 17 AENIEGYVAVMK 2 SHFKIKSDWYVS 126 । 6

107 PYDVTIKANGCIIFISGLED 17 DRNHAEAGEKQLL 34 EHILEYPLEKAGLYLHGV 52 GQEIEGFVIRCH 7 FFFKYKFEEPYL 535 /

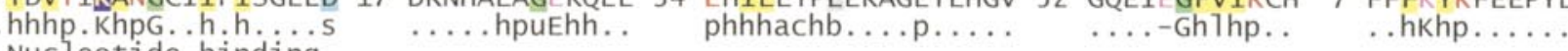
Motif

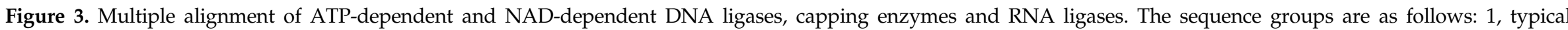

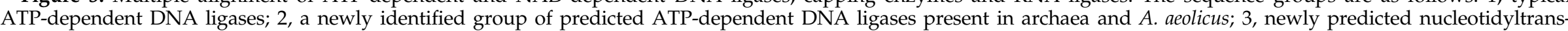

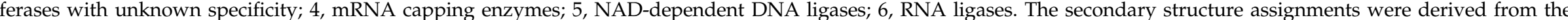

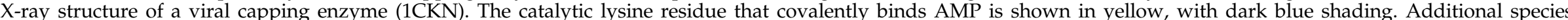

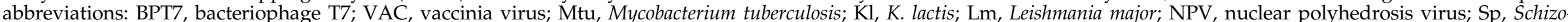

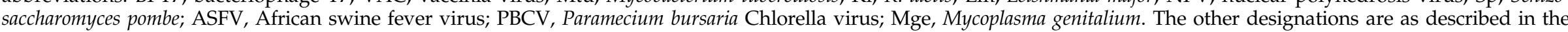
legend to Figure 1. 
have evolved from a common ancestor and have a similar catalytic mechanism. The divergence may have largely arisen from the need to accommodate different nucleotide cofactors.

The iterative searches initiated with ATP-dependent ligase sequences also identified a novel family of predicted ATP-dependent ligases in archaea and Aquifex aeolicus (Figure 3; Altschul \& Koonin, 1998). Further searches started with diffferent members of the ligase superfamily, such as the MCEs, also detected several uncharacterized proteins that are predicted to have the same fold and possess nucleotidyl transferase activity. These include proteins encoded by bacteriophage T4, nuclear polyhedrosis virus and the killer plasmid of Kluyveromyces lactis (Figure 3). Finally, the detection of one of such predicted nucleotidyl transferases in Leishmania is particularly interesting as this organism shows RNA editing which requires an RNA ligase (Benne, 1993). The newly detected, diverged enzyme of the ligase superfamily may be a candidate for this role.

\section{ACT: a novel ligand-binding domain}

Iterative searches seeded with the small subunit of acetolactate synthase (IlvN), an enzyme that catalyzes the synthesis of acetolactate from pyruvate, revealed significant similarity between the core globular domain of this protein and a variety of other proteins and domains, most of which, directly or indirectly, are involved in amino acid and purine metabolism. For example, in a search started with the $E$ coli IlvN sequence, an aspartokinase sequence was detected in the third iteration with an $e$-value of $\sim 10^{-3}$, a homoserine dehydrogenase sequence was retrieved in the fourth iteration with an $e$-value of $\sim 10^{-5}$ and chorismate mutase and RelA were detected in the sixth iteration with $e$-values $<0.01$. The proteins in which this previously unknown domain was identified are: (i) aspartokinases, (ii) chorismate mutases; (iii) prephenate dehydrogenases (TyrA); (iv) prephenate dehydratases; (v) homoserine dehydrogenases; (vi) malate dehydrogenases; (vii) phosphoglycerate dehydrogenases; (viii) phenylalanine and tryptophan-4-monooxygenases; (ix) phosphoribosylformylglycinamidine synthase (PurQ); (x) uridylyl transferase and removing enzyme (GlnD); (xi) GTP pyrophosphokinase/phosphohydrolase (SpoT/RelA); (xii) tyrosine and phenol metabolism operon regulators (TyrR), (xiii) several uncharacterized proteins from archaea, bacteria and plants that contain from one to four copies of this domain (Figure 4). We named this conserved and widespread domain the ACT domain after aspartokinase, chorismate mutase and TyrA.

The structure of 3-phosphoglycerate dehydrogenase (3PGDH) has been solved (Schuller et al., 1995) and provides insight into the structure and functions of the ACT domain. In 3PGDH, ACT is a C-terminal regulatory domain that is well separated from the classic oxidoreductase domain and forms a $\beta$-sheet with appressed helices (a version of the ferredoxin fold according to SCOP). This domain binds L-serine which is the final product of the respective pathway and an allosteric regulator of 3PGDH (Grant et al., 1996). The most conserved portion of the ACT domain is the region at the interface between the first strand and the first helix (Figure 4). Mapping of this conserved motif onto the structural model shows that it is likely to be critical for ligand binding (Figure 5). The characteristic glycine residue followed by a hydrophobic residue in the helix are necessary for maintaining the conformation of the strand-helix interface. In the third position N-terminal of this conserved doublet is a small, polar residue which typically, an aspartate or an asparagine residue (Figure 4). The position at the junction between helix 1 and strand 2 of this domain is again occupied by a small polar amino acid, most frequently an asparagine residue. Both of these residues form hydrogen bonds with the ligand (serine residue) in 3PGDH, and site-directed mutagenesis of these positions alleviates the allosteric inhibition by serine (Grant et al., 1996).

These observations suggest a common ligandbinding mode for all ACT domains whereby the ligand is held in the vicinity of the strand-1-helix-1 interface by means of hydrogen bonds with the two conserved polar residues (Figure 5). The distribution of the ACT domain in enzymes is remarkable in that several of them, e.g. 3PGDH, aspartokinase (Patte et al., 1976) and acetolactate synthase (Vyazmensky et al., 1996), are classic examples of allosteric regulation by the end products of the respective pathways. The presence of the ACT domain in several enzymes involved in the metabolism of different amino acids and in the purine metabolism enzyme PurQ is compatible with the hypothesis of a common origin of allosteric regulation in these functionally diverse enzymes. According to such a scenario, a conserved, evolutionarily mobile module was independently fused to a variety of enzymes, which made them susceptible to the regulation by the respective ligands. This fusion model is consistent with the C-terminal location of the ACT domain in most of these enzymes. The presence of the ACT domain in transcriptional regulators of amino acid metabolism, such as TyrR (Pittard, 1996; Wilson et al., 1995), again indicates that this domain has been recruited for the recognition of the respective amino acids by these regulators. The detection of the ACT domain in GlnD and SpoT/RelA is particularly notable because of the role these proteins play in sensing environmental conditions in the regulation of glutamine synthesis and in stringent response, respectively (Rhee et al., 1985; Cashel et al., 1996). It is likely that the catalytic domains of these enzymes are regulated in response to yet unidentified ligands bound by their ACT domains. The uncharacterized proteins that contain single or multiple copies of the ACT domain may be novel 


\begin{tabular}{|c|c|c|}
\hline Secondary struct & & 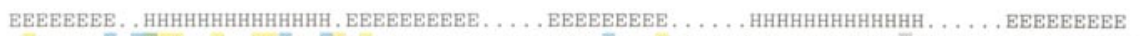 \\
\hline 1PSD_Ec_1127236 & $338-409$ & 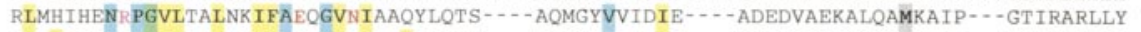 \\
\hline PGDH_Bs_629142 & $52-524$ & IYIQHQDTTGVIGRVGRILGDNDINIATMQVGRK - - -EKGGEAIMMLSF - - DRHLEDKIVKE-LTNVPD- - IVSVKLIDL \\
\hline PGDH_Af_3122861 & $53-527$ & I ISLHED K PGIGRVGTLFGRNNINIAGMIVGRS- - - GDKPGG IQLMLLLVDDPPTPEVLEEM - TKLDG - - IIDATYVEL \\
\hline HDH_BS_2635723 & $50-426$ & URIHVKDEVGSFSKITSVFSERGVSFEKILQLPIK - - -GHDELAEIVIVTHHT SEADFSDI LON-LNDLEV - -VQEVKSTYR \\
\hline HDH_Aae_2622343 & $6-421$ & IRLDAVDRAGVLHEIAGAFSRHGISIESVTQKGA- - - HEGETVPIYIVTHEASEGAIQGALSE-ISEIRW- -VRGEPLRLR \\
\hline DDH_Bs_1303990 & $9-84$ & LMIETPSVPGNLGRVATAIGLLGGDIGEVETVKV- - - - GPNYTMRNITVQVENEEQLQEVIAAVQALGEG - IRLHTVSDE \\
\hline MDH_Ssp_1651735 & $13-88$ & REIAVDASSSEHAEKI IGAVKALDNV - -KLLKVSDRT \\
\hline HAS_BS_1170549 & $4-79$ & TLTVVN SGVLNRITGLFTKRBYNIESITVGHT - . - ETAGV \\
\hline $11 \mathrm{vN}$ & & UT IVVE-GDDKVVEQVIKQ \\
\hline vN_Mtu_2791599 & $7-81$ & MT IVVS - AEDT PLEQITKQ-LNKLIN - -V: \\
\hline IVN_Aae_2984126 & $29-103$ & YNIEGLSVGET - - - HEKGISRMTIEVI - GDDIVIEQVVKQ - LRRLID - -TLKVSDLTD \\
\hline HAS_Ec_124383 & & ILSVLLENESGALSRVIGLFSORGYNIESLTVAPT - - -DDPTL \\
\hline ilv6_s & $79-153$ & VLNCLVQNEPGVLSRVSGTLAARGFNIDSLVVCNT - - - EVVDLSRMT IVLQ-GQDGVVEQARRQ - IEDLVP - -VYAVLDYTN \\
\hline 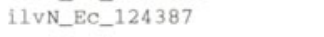 & & IWLLV- - NDDQRLEQMISQ-IDKLED - -VVKVQRNQS \\
\hline & & 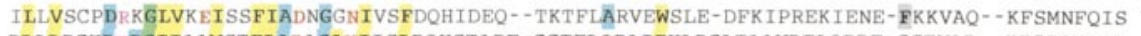 \\
\hline Pur & & ISLDQHSTAPE-GGTE \\
\hline PurO_: & 8 & VEWQLDNFRLSRPELLSAW-SQL \\
\hline 75 & 112 & CNLTHIESRPS - - - RLN \\
\hline W5M & & INLLHIESRKS- - - KRRNSEFEIFVDCDTNREQ \\
\hline PheA_B & $204-281$ & MVMLPQDDQSGALHRVLSAFSWRNLNLSK IESRPT - - - - KTGLGHYFFI IDIEKAFDDVLIPGAMQELEALGCKV \\
\hline TYRA_B & $00-372$ & DLYVDVPDHPGVISEITAILAAERISITNIRI IET - - -REDINGILRISFQ-SDDDRKRAEQCI-EARA - - -EY \\
\hline CHM & $9-276$ & LAFSVPRNVPGALVAPLQLLAQRNINLSRIESRPTKR--SLGEYVFFMDLEASQTEPRLQEALEK -LKQYTE- -VI \\
\hline CHM_ & $194-268$ & IVFELKEDK PGALYHILKEFAERNINLTRIESRPS- - - KKRLGTYIFYIDFENNKEKLEEILK-SLERHT - -TFINLLGKY \\
\hline CHM_BS & -144 & LSISTSAMEEDIHTLN \\
\hline & 72 & DPI - . . . \\
\hline PhhF & & YYLLCPNMINLOLQSLRPK - LEAVPG - -VFGVKRVGL \\
\hline & & S- - - H \\
\hline ASE & & I ......... \\
\hline ASp & 519 & VALLRVPDR PGVASKLFRDIAQQQVDIDLIIQSIH- -..-DGNSNDIAFTVVKDLLNT, \\
\hline AS: & 565 & ISVDMIIQSQRCRINQGTPCRDIAFMVAEGDSSQA \\
\hline 65 & & IVGSGMIGEPGVAAHFFAALAQEI \\
\hline Th & 53 & VSGPGMKGMVGMAARVFAAMSRARI SVVLITQSSS - - - EYSI \\
\hline Th & 72 & INIVAIAQGSS - ...-ERSISVVVNND - - -DAT \\
\hline ASPKIN3_Ec_41 & 7 & LHSLNMLHSRGFLAEVFGILARHNISVDLITTSEV - - - SVALTLDTTGSTSTGDTLLTQSLLME-LQRILM - - DMGYDPMVT \\
\hline & & $\mathrm{AD}$ \\
\hline & & DEP \\
\hline G1 & 86 & LHGARITTI - . - C C \\
\hline 390 & 96 & IVSSMTNTR - ..... H \\
\hline 162 & & - -VMDLRRVIS \\
\hline & 02 & INIMRKIRVMPD - - VIKVTRNRN \\
\hline $\mathrm{Re}$ & & KVNVLGVASRSD - - - TKQQLAT IDMT IEIYNLQVLGRVLGK - LNQVPD - -VIDARRLHG \\
\hline & & TKK-.....-I \\
\hline .9_At_282992 & $344-417$ & ELCAKDRVGLLSEVTRILREHGL SVSRAGVTTV - - . - - GEQAVNVFYVKDASGNPVDVK: \\
\hline D_Af_2649579 & $95-165$ & LEVYAESTKVGIVAGVASALÄNAGISIRYILAEDP - - - ELSVESKLTVVT - - -ETKI PGAVVEE-ILRV - - - EGVEKVLIS \\
\hline Mj__2826433 & & VVSVIGQDRTGIVAGISKVLAENNANILDISQ-TI- - -MDNLFAMIMLVDISNAKVDFATLKKE-LEKAGE- -ELGVQVIVQ \\
\hline 33_Ph_3131505 & & EVELIVVDKPGVLAKISGT LGRHGINILFNESEEL- - -ESLGMAAIVAIVDISNSDVSVKELEG - VLAKIE- -EVKEVKIRE \\
\hline _Bs_2337814 & $148-220$ & AILVVHNDKFGTIAGVANVLAKFSINVGHMEVARK - - - DIGQLALMTIEVDQNIDDHILDELSK - LPN - - IIQVTKIAD \\
\hline 061 & & FEYEIQVNRPGLLGDISSLLGMLSINIVTISGVDL- - -SRR--GMLLRCRHIDLINRLESILKS-METIKV- -AKLREPRLR \\
\hline 264966 & & TLSVELEDRPGQLLKVLQPISGMGGNIVGIVHQRG----KKTPLNRLPVEISFKMDSEKVQK \\
\hline-24145 & 17 & LLRIELADRPGSLGLAVALGSVGGDILSLDVVER----SGGY-AIDDLVIEVPSGAMPDKLITA-FESLPGV-RVDSVRPHS \\
\hline 35_Mta_2622347 & $5-77$ & ALSIKTVERPGVLSEITGMIASRNINITYAHLYV- - - ERDGHGAIYMEL- -EDIDDRESLINE-LKSSST - -VLDVKIHRS \\
\hline MTH416_Mta_2621480 & $7-81$ & NLVIELRT̄ APGQLVSVLEPLGSTGVNIVTVI HERD - - - REYGPVVPVQLT - VEGDRETLDAAIG - RLQEQG - VNI IEMDGA \\
\hline 2649166 & $4-79$ & GLRI IAENK I GVLRDLTT I IAEEGGN ITFAQTFLI - - - KHGEHEGKALIYFEI EGGDFEK I LER-VKTFDY - IIEIEEEES \\
\hline MJ1601_Mj_2842611 & $3-79$ & TIDIELKDKPGELLRVLTPISKYGANVISIIHSRE-- - EKRGGKVPVRIVIDVDDKDKLKKILE-DLEKEGA-IIKKIDGKD \\
\hline MJ1458_Mj_2128872 & $4-77$ & GISIEAENKVGVLHKLTGILSELGGNITYTQQFIK- - - DDGKIG̈FIYMEV- -EGIKDIEELKRR-MESCEC--VKSFEIHSS \\
\hline & & 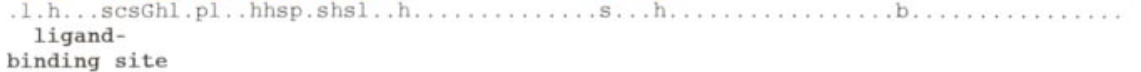 \\
\hline
\end{tabular}

Figure 4. Multiple alignment of the ACT domain superfamily. The sequence groups are as follows: 1, 3-phosphoglycerate dehydrogenase and related dehydrogenases $(\mathrm{HDH}$, homoserine dehydrogenase; and $\mathrm{MDH}$, malate dehydrogenase); 2, small subunits of acetolactate synthases; 3, formyltetrahydrofolate deformylases (PurU enzymes); 4, prephenate dehydratases (PheA, TYRA), chorismate mutases (CHM) and regulators of aromatic amino acid biosynthesis operon expression (TYRR, PhhR); 5, aspartokinases; 6, uridylyl transferases (GlnD), guanosine polyphosphate 3'-pyrophosphohydrolases (SpoT) and GTP pyrophosphokinases (RelA); 7, uncharacterized proteins containing predicted ACT domains. The secondary structure assignments were derived from the 3-phosphoglycerate dehydrogenase X-ray structure (1PSD). The positions of the aligned regions in each of the sequences are indicated by numbers in front of the alignment. The other designations are as described in the legend to Figure 1. Additional species abbreviations: Ssp, Synechocystis sp.; Pa, Pseudomonas aeruginosa; Av, Azotobacter vinelandii; Ph, Pyrococcus horikoshii; Mta, Methanobacterium thermoautotrophicum.

sensors or regulators that bind specific ligands, primarily amino acids.

\section{The immunoglobulin-like domain in transcription factors (the TIG domain)}

The transcription factors of the rel/dorsal/NFkB family have been shown to possess a bipartite DNA binding structure which has two distinct $\beta$-strand-rich domains (Ghosh et al., 1995; Muller et al., 1995). The $\mathrm{N}$-terminal domain is a $\beta$-barrel similar to that seen in other DNA-binding domains proteins, such as p53, T-box and the STATs (cytochrome $\mathrm{F}$ fold in SCOP). The C-terminal domain is an unusual immunoglobulin (Ig) fold domain (Ig superfamily, type E according to SCOP) which we designated the TIG domain, after transcription factor IG. Sequence and structural comparisons 


\section{ACT domain}

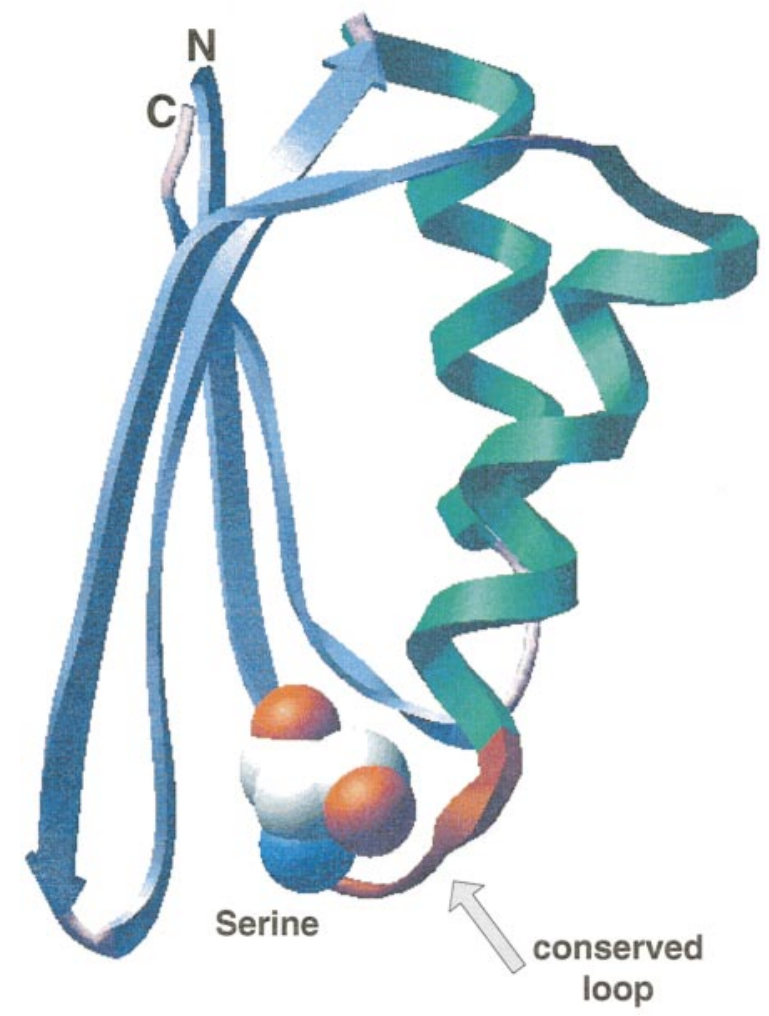

Figure 5. A structural model of the ACT domain with a bound ligand. The domain structure was extracted from the PDB entry for 3-phosphoglycerate dehydrogenase (1PSD). The conserved loop between strand-1 and helix-1 which is the primary determinant of ligand binding is shown in red.

clearly indicate that the NFAT transcription factors possess a two-domain DNA-binding structure similar to that in NFKB (Chen et al., 1998). However, a direct sequence-based identification of relationships of this C-terminal Ig-like domain beyond the obvious connection between NFKB and NFAT has not been reported so far.

In order to investigate the relationships and possible origin of these domains, we conducted a systematic analysis with different starting queries. These PSI-BLAST searches recovered a vast superfamily of proteins with a conserved domain similar to the C-terminal Ig-like domain of NFAT and NFkB. The searches initiated with different starting points consistently retrieved essentially the same set of sequences at $e$-values $<0.01$, which reinforced the significance of the observed relationships. This was also supported by secondary structure predictions using the PHD program for the newly identified members. The diverse TIG domain superfamily (Figure 6) includes transcription factors of different families such as the Olf-1/ Unc-3 family (Prasad et al., 1998), including the
Saccharomyces cerevisiae SPT23 and MGA2 (Yiv1; Zhang et al., 1997), and the CBF1(Suppressor of hairless) family (Fortini \& Artavanis-Tsakonas, 1994; Schweisguth, 1995). Multiple copies of the TIG domain were also detectable in the extracellular regions of several proteins, such as the tyrosine kinases of the MET/RON family (Vande Woude et al., 1997) and probable adhesion molecules such as plexin (Satoda et al., 1995) and SEX (Maestrini et al., 1996), as well as an extracellular protein which is the major virulence determinant of the fish pathogenic actinomycete Renibacterium (Barton et al., 1997). In addition, the Sec5 subunit of the animal secretory exocyst complex (Kee et al., 1997) also contains a TIG domain at its extreme $\mathrm{N}$ terminus. Some of the searches started with the TIG domains also detected the Ig-like domain of the bacterial cyclodextrin glucan transferases that has been identified previously on the basis of structural comparisons (Hofmann et al., 1989).

Inspection of the multiple alignment of TIG domains showed that the sequence conservation mapped to hydrophobic residues that form the structural basis of the $\beta$-strands (Figure 6) as well as a characteristic $\mathrm{N}$-terminal loop between strands 2 and 3. The identification of the Ig-like TIG domains in some of these proteins has important functional and evolutionary implications. Proteins containing the TIG domain have been shown to contact DNA either as dimers (NFkB; Ghosh et al., 1995; Muller et al., 1995) or as monomers (NFAT; Chen et al., 1998). The TIG domain plays a major role in the dimerization of NFKB (Ghosh et al., 1995; Muller et al., 1995). The differences in the structural context of this domain in NFAT and NFKB suggest that the TIG domain is versatile in its DNA and protein contacting activities, with loops between the strands of the Ig domain being crucial for this process (Chen et al., 1998). Olf-1 binds DNA as a dimer and has an additional $\mathrm{Zn}$ binding motif which is located upstream of the TIG domain and is required for specific DNA binding (Hagman et al., 1995). It seems likely that in Olf-1, similarly to NFkB, the TIG domain performs a dual role, being involved both in dimerization and in DNA binding. The TIG domain is a likely candidate for a role in non-specific DNA binding by Olf-1 rather than the purported helix-loop-helix (HLH) domain (Wang \& Reed, 1993), for which no statistical support could be obtained (L.A., unpublished observations).

The CBF family of transcription factors are DNA-binding proteins that act as repressors of transcription in the Notch pathway (Fortini \& Artavanis-Tsakonas, 1994; Schweisguth, 1995). These proteins bind to NFkB-like target sequences (Shirakata et al., 1996) and interact with NFkB and $\mathrm{C} / \mathrm{EBP}$ in the IL-6 gene regulatory region (Kannabiran et al., 1997). Taken together with the presence of the TIG domain, this suggests a mode of DNA binding and protein-protein interactions similar to that of NFкB. Finally, the Arabidopsis protein F1N21.9 appears to be the ortholog of the 
Secondary Structure KBF1_HS_1633504

BF3_HS_1708619

DIF_Dim_1708619

Dor_Dim_118792

NFATX_Mm1842165

NFAT_Mm_11353776

CBF_HS_548675

Su_H1_Dm_103229

CBF_Hr_2116585

CBF2_Mm_2052119

lag1_Ce_1245216

SPT23_Sc_548965

C26H5.05_Sp_23988

OLF-1_Mm_423422

Unc3_Ce_2981061

F1N21.9_At_2760324

T05C1.6 Ce 861376

MET_HS_2078456

Sex_Hs_1711384

Plexin1_Mm_2137644

ECP57.1 Rs 98700

ECP57.2 Rs 98700

T23G7.4_Ce_1132533

rsec5 $\mathrm{Rr}_{2} 2827158$

consensus $/ 80$ \%

1CGT_BCi_493930
EEEEEE , . EEE . .

EEEEEE

EEEEEEE

EEEEE.

EEEEEEE

EEEEEEEEEE 245-355 PNASNLKIVRMDRTAGCVTGGEEIYLLC-DKVQKDD IQIRFYEEEENGG - -VWEGFGDFSPTDVHRQFAIVFKTPKYKDIN- - . . . . - ITKPASVFVQLRRKSDLETS 223-331 PGASNLKSTR

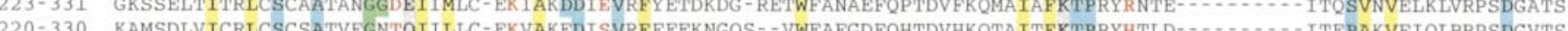
595-703 SAOEI P̈HIEKYSINSCSVVGGEMIVT-

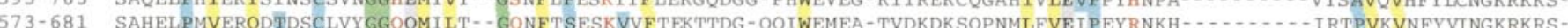
348-450 A 378-480 ASPVTP-VP TVW 379-481 SKPVTP-VPVYHSLOLN-GGGVAMLEYPI $377-479$ REPVTP-VPLISTH 556-664 ANPISP-CPVVGSLEVD-GHGEASRVELHGRDFK PNLKVWFGATPVET - . - TFRSE- . . . . $\ldots \ldots$. 503-620 ALNKPIOPVI AOG 525-630

$5253-745$ DVSHAPLISRIPQGPINGGIEVTLL-

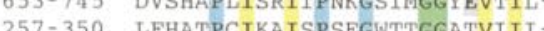
$257-350-36100$

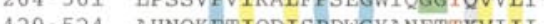
$129-524$ A 652-753 FSYVDP̄VITSISP̄KYG̈PMAGGTLLTLT 840-1027 YSFVTPTFDQVSPSRGPASGGTRLTIS 954-1050 FTFVTPTFYRVSPSRGPLSGGTWIGIE167-232 PAVNKP-ASGLQPPAGPLGGGTVVKVD -c 233-325 YFGSAP-TATLEPKTGPRDGGTVVKVN -

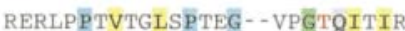
RSRQPPLVTGISPNEG - - IPWTKVTIR-h. .h.s.s. GGpbh. CNFKDGLSVEKFGSNLAISTQ - CWSET - ........... ANFFNGLVCLFGDNPAAVTF-SWSES - . . . . . . TIIATCPPATNAG - -

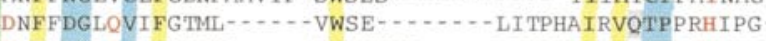
ENFFEGLQVAFGTASP -...... NWGESVQ-...-. LISPHAIRVTTPPKHSAG - - SFLCDPTESTWSCMFGNAQV - PFEI IKEG - ....... - -VIRCEAP-QCGPG VLSCVIP-PSAKP

GNYLNSGNST̄RISIGGKTCTLKSVSNS - . . . . . . . . . . ILECYTPAQTIST - AIVCISP-LSTLG-SHLNAGSDVAVS IGGRPCSF-SWRNSR - ......... SNLFGASOVSFGDKPGTDI - AVAQDGN …….... SLTVKTPAVDAAG

DSRVTFGDNEATEI - - HIAQDGN -

GENLGNDQSDVVIMLIFICGIDS - LWSMKWK - ...... Gp.h.ss.ps.b. .

1. hbsP. .

QIKVTIPSVA-AG-

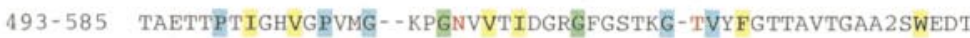

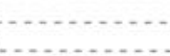
TVPVTFQNYNSSE--. VVEVTSYKSKQFCKG - PVDVTQYKSKTYSRG EVVQIRNFCNGQÄIS ANKLIKIDANRETSIFSY SQAPITAIDRANISSPG SAPIVNINRAQLSNPE--PVEVKVSTPNGSĀTA EVRIATKSGGKGSSNV DIVIATKSGGKGSSNV D1.1........ OVFVSTDTNNENNNDDL

NYAVKVAASGYNSTN- -
EEEEEEEE

FETK DPKPFLYPEIKD DSTEFYYTERT EALPFEYYPMDSD QSORETYTPVLMK QSQRFTYPVIMK QPQHTYYPTPA TSETFTYPEPG TSEPF

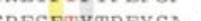
SGTTYTEYSA GATPSTER KAIFTYVDDTDR APVMFTYEDNLDDN TPGRFIYTALNEP TPLRFSYITLAEP EIREFEYREKPDT TASEFTYEPQSAH DPIVYEIHPTKSF VKYNYTEDPTILR | -GGETVTYESFH | KFRVFITQIGPLE \3 FKLLKPEKIGIL / apb.

AYNNFTILTGDQV

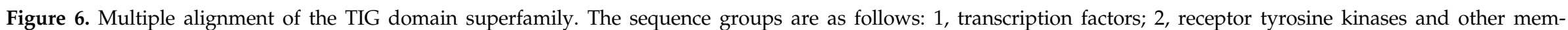

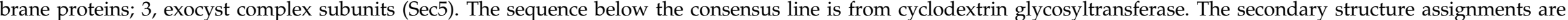

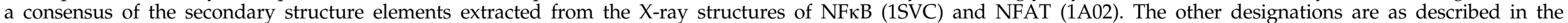

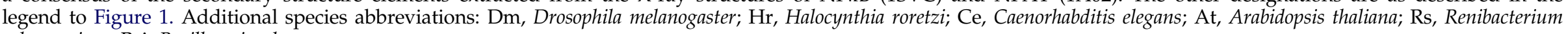
salmonarium; Bci, Bacillus circulans. 
CG-1 protein from parsley (whose cDNA has been cloned only partially), which is a light-induced DNA-binding protein with a specificity towards the CGCG motif (da Costa e Silva, 1994), and an uncharacterized Caenorhabditis elegans protein. This observation is of interest as it suggests that TIG domain-containing transcription factors are ubiquitous at least in the crown group of eukaryotes.

The presence of multiple copies of the TIG domain (hitherto unnoticed) in the extracellular regions of the Met family receptor tyrosine kinases, plexins and the related SEX receptor molecules (which, instead of the kinase domain, contain an intracellular Ras GAP domains; L.A., unpublished observations) is consistent with the traditional extracellular role of Ig-like domains. The tyrosine kinases of this family function as receptors for hepatocyte growth factors and also interact with the extracellular matrix; the TIG domains likely mediate some of these interactions (Vande Woude et al., 1997). The TIG domain superfamily is notable in that a clear relationship detectable at the sequence level was established between extracellular Ig-like domains and the intracellular ones seen in the transcription factors.

\section{A $\beta$-propeller domain in Rag-2}

The diversity of antigen receptors (namely the immunoglobulins and T-cell receptors) in vertebrates depends on combinatorial shuffling of individual modules at the DNA level mediated by the so-called V-D-J recombinase. This recombinase, which also possesses a transposase activity, consists of two subunits, RAG-1 and RAG-2 (Oettinger, 1996; van Gent et al., 1995, 1996). The crystal structure of RAG-1 revealed that it combines a RING finger with a $\mathrm{C} 2 \mathrm{H} 2 \mathrm{Zn}$ finger into a novel DNA-binding structure without recognizable similarity to any other recombinases (Bellon et al., 1997). The second subunit, RAG-2, does not show significant similarity to any other proteins in standard database searches. However, PSI-BLAST searches initiated with different $\beta$-propellers of the kelch-repeat type (Bork \& Doolittle, 1994), retrieved the previously well-characterized proteins, such as kelch itself, $\mathrm{HCF}$, fungal galactose oxidase, scruin and a family of poxvirus proteins, as well as Rag-2. Rag-2 emerged with the same level of statistical significance as galactose oxidase with a known $\beta$-propeller structure in a search initiated with the N-terminal propeller domain of $\beta$-scruin (e-value $\sim 10^{-4}$ in the third iteration).

On the basis of the galactose oxidase structure, the position of the characteristic glycine doublets typical of the kelch domain were identified in Rag2 and the individual $\beta$-barrel repeats of the propeller were demarcated (Figure 7). Inspection of the multiple alignment of the repeats from Rag- 2 with those of other kelch proteins shows that while the repeats in Rag-2 are divergent, they maintain the conserved hydrophobic residues corresponding to the individual strands of the $\beta$-barrel (Figure 7).
Rag-2 contains five clearly detectable kelch repeats, but additional, permuted copies may be present at the ends of the proper repeats which would result in a six or seven-bladed $\beta$-propeller structure for Rag-2. The linker regions between the kelch repeats in Rag-2 are of similar length to those in the fungal galactose oxidase, which suggests that they curl around the next repeat and the individual repeats are placed at a deeper angle with respect to one another than in such proteins as Kelch or HCF. In addition to the $\beta$-propeller domain, the only other portion of Rag-2 that is predicted to possess globular structure is a putative cysteine-rich, metal-binding domain located near the $\mathrm{C}$ terminus. The dissection of the Rag-2 sequence into these domains has two important implications. Firstly, like other $\beta$-propellers off this class, Rag- 2 is expected to be capable of versatile protein-protein interactions and is likely to play a central role in the formation of multisubunit complexes involved in recombination. Secondly, there was extensive speculation that Rag proteins may derive from the genes of some transposable element that has been inserted in the vertebrate germ line (Agrawal et al., 1998). The identification of typically "cellular" eukaryotic domains in these proteins makes this hypothesis highly unlikely. Rag-2 may have evolved from a pre-existing cellular kelch-repeat protein. Given the catalytic activity of a number of kelch-repeat $\beta$-propellers, for example, galactose oxidase and sialidases (Bork \& Doolittle, 1994), it is possible that Rag-2 plays a structural as well as a catalytic role in the recombinase reaction. We are aware of an independent analysis that arrived to very similar conclusions on the domain architecture of Rag-2 using a different computational technique (Callebaut \& Mornon, 1998).

\section{Concluding remarks}

It must be emphasized that this work by no means presents a comprehensive bench-marking of PSI-BLAST. Some efforts in this direction have been recently published by this and other groups (Huynen et al., 1998; Rychlewski et al., 1998; Wolf et al., 1999). Clearly, much additional work is required in order to fully evaluate the benefits and pitfalls of using iterative database search at large scale and in an automated regime and to establish the optimal strategy for such applications. Furthermore, the present analysis involved a relatively permissive cut-off for inclusion of sequences into profiles and the procedure to some extent varied for different protein superfamilies. Thus, we describe here an approach to protein superfamily analysis that should be applied in a human-controled fashion, which involves careful examination of diagnostic sequence and structural motifs, rather than a protocol for automated analysis.

These limitations and cautionary notes notwithstanding, the results presented here demonstrate 
EEEEE . . EEEEEE

. EEEEEE

EEEEE .

70: SEVNELDNESTPAVLIFGG INTARP - - TDYLNSASMFLYHLDRN - - NWNFYGTMLE 122: PRNYHAAAYFHGKVYLFGGYNPLHC--IKGKMQATSTTFQLTLDVKQWRRRADMPS 176: ARAHHGVTIMDERIFVFGGKDSN-----GNIIASVEMYEPELD- - QWTSLASIPE 224: PLMGSAVTNNEGLIYVVGGLTTKKEKNQEGVLSNKIYCFDPLNN - - KWYRKPPLPC 278: PRAFASATTQNKKIWIWGGASLSEG--GTLASTTSVDIWDPKKG - -RFEQHLIFDS 330: PKHCLAVTKAGTQVFIIGGMSSK--- -ENSSLAEVQVYDRKRDILQKCAFLPVSL 574: HATGDIQDTSIPVIIAIGGVDPQDP--MNVSYGRSVFQYHPLKD- - RWEFFGFMSL 626: PRNHHAAAYYRGAIYVTGGCDPHIR--CWGEMVATKMTFVYRLSSNKWTRVADMHS 680: ARSHHSMVVFNDSIYVIGGRDDS-----GRLSASVESYVPALD- - EWNQEKPMPL 728: PRMGMAVVSHGGYLWVMGGVTSTKGGNINPPVLDDVICYDPVFK - -HWVSGKPLRI 782: ARAFGSAVVCDDKIWLCGGAAPSQDENNYLVSIPAIDVYDNEAL - - EWIQKATLSC 836: PRHSSVVVALESCLYLIGGINSH----ELSAINRNELYTTDSDTVQSIRELPVQL 392: RTVPRKPVGMPKILLVIGGQAPK- - - - -AIRSVEWYDLREE- - KWYQAAEMPN 438: RRCRSGLSVLGDKVYAVGGFNGS- - - - - LRVRTVDVYDPATD- - QWANCSNMEA 485: RRSTLGVAALNGCIYAVGGFDGT - - - - TGLSSAEMYDPKTD- - IWRFIASMST 532: RRSSVGVGVVHGLLYAVGGYDGF-- - - TRQCLSSVERYNPDTD- - TWVNVAEMSS 581: RRSGAGVGVLNNILYRVGGHDGP-- - - - MVRRSVEAYDCETN - - SWRSVADMSY 628: CRRNAGVVAHDGLLYVVGGDDGT - - - - - SNLASVEVYCPDSD - - SWRILPALMT

82: SHASHLYAEGGQEIYIFGGVASD-...- - SQPKNDLWVLNLATSQFTSLRSLGE 133: PRLGHASILIGNAF IVFGGLTNHDVA- - - DRQDNSLYLLNTSSLVWQKANASGA 187: GRYGHTISCLGSKICLFGGRLLD-- - - YYFNDLVCFDLNNL- - NTSDSRWELA 242: ARAGHVAFTFSDKLYIFGGTDGA- - - - NFFNDLWCYHPKQS - - AWSKVETFGV 292: PRAGHAASVVEGILYVFGGRASD - - - - - GTFLNDLYAFRLSSKHWYKLSDLPF 34 3: PRSSHTLSCSGLTLVLIGGKQGK---.--GASDSNVYMLDTS- - RFRLGSVPTT 286: YRCSFAVAVLDNIIYMMGGYDQS-----PYRSSKVIAYNTCTN--SWIYDIPELK 335: PRSNCGGLADDEYIYCIGGIRDQ- - - - - DSSLTSSIDKWKPSKPYWQKYAKMR 384: PKCDMGVAMLNGLIYVMGGIVKG-- - - - DTCTDALESLSED--GWMKHQRLPI 430: KMSNMSTIVHDGKIYISGGYNNSSVVNV-- - ISNLVLSYNPIYD- - EWTKLSSLN I 481: PRINPALWSAHNKLYVGGGISDDV--- - -RTNTSETYDKEKD- - CWTLDNGHVL

32: PRHGHRAVAIKELIVVFGGGNEG - - - - - IVDELHVYNTATN - - QWFIPAVRGD

81: GCAAYGFVCDGTRLLVFGGMVEY-- - - - - GKYSNDLYELQAS - - RWEWKRLKAK 136: PRLGHSFSLVGNKCYLFGGLANDSED-- - PKNNIPRYLNDLYI - LELRPGSGVVA 206: AVVYTEKDNKKSKLVIYGGMSGC----- RLGDLWTLDIDTL- - TWNKPSLSGV 254: PRSLHSATTIGNKMYVFGGWVPL - - - - - -VMDDVKVATHEK - - - EWKCTNTLAC 232: HPSLKPARRTRDVLIIIGGWLHR--.-- - QACDRIEWFDPENN - - CWKVSQQKLP 280: TLAYHGSAIVDGILYLFGGSTGQ--..--RTRCETWKLSTET -WQWDRCNNMME 329: NYISNSSVVYDGRIYVFGGQNFREITRTAV - RSRTGEVFDPKTN - - KWTETASLSD 382: MRSDCAAEVFENQIYVSGGFNGD----- MILASVEVYNPIGN - - VFSRTVDLPY 429: PITGHCLLNHGNQLLIVGGFDGA--..- - ERQNK IWMWHRTG - - EWQQRPEKLI 226: MFCPGISMDGNGQIVVTGGNDAK - - - - - - KTSLYDSSSD- - SWIPGPDMQV 270: RGYQSSATMSDGRVFTIGGSWSGG----- - VFEKNGEVYSPSSK - - TWTSLPNAKV 322: TADKQGLYRSDNHAWLFGWKKGSV--FQAGPSTAMNWYYTSGSG - -DVKSAGKRQS 383: CGNAVMYDAVKGKILTFGGSPDYQ- - -DSDATTNAHI ITLGEPG - TSPNTVFASN 439: RTFHTSVVLPDGSTFITGGQRRGI- - - - PFEDSTPVFTPEIYVPEQDTFYKQNP 16: IQPGF SLMNFDGQVFFFGQKGWP---- - KRSCPTGVFHLDVK-HNHVKLKPTIF

68: CTFKGSLESEKHQYIIHGGKTPN-- - - - NEVSDKIYVMSIV--CKNNKKVTFR

140: HSINVVYSRGKSMGVLFGGRSYM- - - - - PSTHRTTEKWNSVADCLPCVFLVDF 203: GLSFHVSIAKNDTIYILGGHSLA - - - - NNIRPANLYRIRVD-LPLGSPAVNCT 258: VSSAILTQTNNDEFVIVGGYQLE----NQKRMICNIISLED-NKIEI REMETP

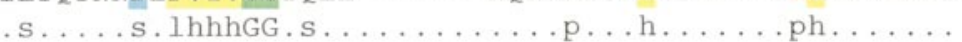

B-scruin_Lp_2497945

Kelch_Dm_1170644

TEA1_Sp_3618212

A55_VAC_137403

HCF1_Hs_1708193

SPE26_Ce_1711486

1GOF_494052

RAG2_Hs_2498830

consensus/80웅

Figure 7. Multiple alignment of the kelch-repeats detected in Rag-2 with known kelch repeats. The alignment shows all repeats identified in Rag-2 and selected proteins known to contain the kelch domain; the repeats from each of the proteins are numbered consecutively from the $\mathrm{N}$ to the $\mathrm{C}$ terminus. The numbers in the second column indicate the number of the first residue of each repeat in the respective protein sequence. TEA1 is a cell polarity protein, HCF1 is host cell factor-1 (a protein required for the transcription of immediate early genes of herpes simplex virus), 1GOF is galactose oxidase from Hypomyces rosellus. The secondary structure assignments were derived from the 1GOF structure. The other designations are as described in the legend to Figure 1. Additional species abbreviation: Lp, Limulus polyphemus.

the significant potential of iterative sequence database search in detecting subtle but functionally and evolutionarily important structural relationships between proteins. At the same time, they show that detailed examination of protein superfamilies that allows an optimal choice of queries to initiate the iterations is critical for the realization of this potential. Thus, in principle, a comprehensive exploration of structural relationships between proteins using sequence analysis should proceed by 
systematically identifying all protein superfamilies in the NR database and then performing iterative searches with appropriately selected starting points, in order to detect diverged members of these superfamilies and join some of them into higher level classes. A corollary of this is that protein classification and structural characterization may be regarded as an autocatalytic processes: the better the resolution of superfamily analysis, the greater the opportunities for detecting ever more subtle relationships. Given the parallel progress in structure determination and sequence and structure comparison methods that is currently observed, a complete hierarchical classification of the protein universe, with a reliable structural prediction for each family, however challenging a task, may be in sight.

\section{Material and Methods}

\section{Databases}

Standard database searches were performed using the non-redundant (NR) protein database at the NCBI. The structural databases used here were PDB and SCOP (Structural Classification of Proteins; Murzin et al., 1995; Hubbard et al., 1999). SCOP employs a manual process to identify structural relationships between proteins and classifies them into a four-level hierarchy. This hierarchy from top to bottom reflects the protein structural class in terms of secondary structural elements ( $\alpha$-helices and $\beta$-strands), a general structural relationship in the arrangement of these elements (fold), an inferred evolutionary relationship (superfamily), and a statistically highly significant sequence similarity between proteins (family). In contrast, the FSSP database classifies proteins by clustering them according to Z-scores, a measure of alignment between the backbones of two structures. Throughout this analysis, we adopted the SCOP classification of folds. Coordinates for protein structures were obtained from PDB.

\section{Database searches}

The principal search tool used in this study was PSIBLAST (Altschul et al., 1997; Altschul \& Koonin, 1998). Briefly, the program constructs a position-dependent weight matrix from multiple alignments generated from the BLAST hits above a certain expectation value (e-value) and carries out iterative database searches using the information derived from this matrix. PSIBLAST-C and R options were used to save and retrieve the position-dependent weight matrices (profiles), respectively. Typically, the profiles were built either by searching with a query sequence against the NR database for a fixed number of iterations or to convergence, or alternatively, against a data set comprised of proteins known to belong to a given superfamily. Generally, an expectation value threshold of 0.01 was used for inclusion of sequences into the matrix for the next iteration. In some cases, however, profiles were built with variable thresholds for each iteration in order to ensure the exclusion of apparent false positives. In order to minimize the risk of including false positives into profiles, the searches were typically carried out using the sequences of the predicted globular domains only. The likely globular domains were delineated by masking compositionally biased regions with the following programs: SEG, with the parameters window size 45, trigger complexity 3.4 and extension complexity 3.75 (Wootton \& Federhen, 1996), for detection of different types of regions with a low compositional complexity; COILS, for coiled coil regions (Lupas, 1996); and PHDhtm for hydrophobic transmembrane helices (Rost et al., 1995). All these procedures as well as batch database searches and clustering of sequences by similarity were carried out using the scripts of the SEALS package (Walker \& Koonin, 1997). The currently accepted default cut-off for inclusion of sequences into profiles by PSI-BLAST is 0.001 rather then 0.01 as employed in this analysis (Altschul \& Koonin, 1998; http://www.ncbi.nlm.nih.gov/cgi-bin/BLAST/nph-psi blast). The protocol described here is generally not suitable for large-scale, completely automated analyses using PSI-BLAST and must be applied in a controled manner. More specifically, this analysis included examination of the final or, if necessary, intermediate results of the PSI-BLAST searches for the conservation of sequence and structural motifs that are diagnostic of a particular protein superfamily (Bork \& Koonin, 1998; Altschul \& Koonin, 1998). Additional precautions, such as masking compositionally biased regions in the database and running a limited number of iterations may be required for implementing an automated procedure based on PSI-BLAST (e.g. Wolf et al., 1999).

\section{Multiple alignments}

For constructing multiple alignments, the high-scoring segment pairs (HSPs) generated by PSI-BLAST were fed into the multiple alignment program CLUSTALX (Thompson et al., 1994) and re-aligned using different gap opening and extension parameters and the BLOSUM series of matrices. This procedure was particularly effective for compact domains that do not contain large insertions or deletions. Alternatively, for domains with variable-size insert and gap regions, the GIBBS sampling procedure as implemented in the MACAW and MGIBBS programs was used to identify conserved motifs (Neuwald et al., 1995; Schuler et al., 1991). For all constructed alignments, the key motifs were mapped on the known three-dimensional structures and the alignments were extended and modified (if necessary) on the basis of the compatibility with the structures.

\section{Structure manipulations}

PDB files were visualized using the SWISSPDB-Viewer program. This program was also used for constructing structural alignments between a target sequence and a template structure and submitting them for crude structural modeling using the PROMODII program which applies the GROMOS energy minimization method (Pietsch, 1996). The structural alignments between the target and the template were manually improved in order to achieve a global reduction in the potential. This modeling protocol does not aim at predicting fine structural details of the target proteins but allows one to visualize both the general similarity to the template and major distinctions, such as large insertions and deletions. Secondary structure predictions were carried out using the PHD program with multiple alignment inputs (Rost \& Sander, 1994). Additional assessments of the structural relationships were performed using the Zega procedure which computes the probability of two aligned 
sequences adopting the same structure (Abagyan \& Batalov, 1997).

\section{Acknowledgments}

We are grateful to Michael Rozanov for his participation in the early stage of the HSP70 superfamily analysis.

(C) 1999 U.S. Government

\section{References}

Abagyan, R. A. \& Batalov, S. (1997). Do aligned sequences share the same fold? J. Mol. Biol. 273, 355-368.

Abdullah, K. M., Udoh, E. A., Shewen, P. E. \& Mellors, A. (1992). A neutral glycoprotease of Pasteurella haemolytica A1 specifically cleaves O-sialoglycoproteins. Infect. Immun. 60, 56-62.

Agrawal, A., Eastman, Q. M. \& Schatz, D. G. (1998). Transposition mediated by RAG1 and RAG2 and its implications for the evolution of the immune system. Nature, 394, 744-751.

Altschul, S. F. \& Koonin, E. V. (1998). Iterated profile searches with PSI-BLAST - a tool for discovery in protein databases. Trends Biochem. Sci. 23, 444-447.

Altschul, S. F., Madden, T. L., Schaffer, A. A., Zhang, J., Zhang, Z., Miller, W. \& Lipman, D. J. (1997). Gapped BLAST and PSI-BLAST: a new generation of protein database search programs. Nucl. Acids Res. 25, 3389-3402.

Aravind, L. \& Koonin, E. V. (1998). Phosphoesterase domains associated with DNA polymerases of diverse origins. Nucl. Acids Res. 26, 3746-2752.

Aravind, L. \& Koonin, E. V. (1999). DNA polymerase $\beta$-like nucleotidyltransferase superfamily: identification of three new families, classification and evolutionary history. Nucl. Acids Res. 27, in the press.

Aravind, L., Leipe, D. D. \& Koonin, E. V. (1998). Toprim-a conserved catalytic domain in tyupe IA and II topoisomerases, DnaG-type primases, OLD family nucleases and RecR proteins. Nucl. Acids Res. 26, 4205-4213.

Arigoni, F., Talabot, F., Peitsch, M., Edgerton, M. D., Meldrum, E., Allet, E., Fish, R., Jamotte, T., Churchod, M.-L. \& Loferer, H. (1998). A genomebased approach for the identification of essential bacterial genes. Nature Biotechnol. 16, 851-856.

Barton, T. A., Bannister, L. A., Griffiths, S. G. \& Lynch, W. H. (1997). Further characterization of Renibacterium salmoninarum extracellular products. Appl. Environ. Microbiol. 63, 3770-3775.

Bellon, S. F., Rodgers, K. K., Schatz, D. G., Coleman, J. E. \& Steitz, T. A. (1997). Crystal structure of the RAG1 dimerization domain reveals multiple zinc-binding motifs including a ovel zinc binuclear cluster. Nature Struct. Biol. 4, 586-591.

Benne, R. (1993). RNA editing in mitochondria of Leishmania tarentolae and Crithidia fasciculata. Semin. Cell Biol. 4, 241-249.

Berger, J. M., Fass, D., Wang, J. C. \& Harrison, S. C. (1998). Structural similarities between topoisomerases that cleave one or both DNA strands. Proc. Natl Acad. Sci. USA, 95, 7876-7881.

Bernstein, F. C., Koetzle, T. F., Williams, G. J., Meyer, E. E., Jr, Brice, M. D., Rodgers, J. R., Kennard, O.,
Shimanouchi, T. \& Tasumi, M. (1977). The Protein Data Bank: a computer-based archival file for macromolecular structures. J. Mol. Biol. 112, 535-542.

Boll, M. \& Fuchs, G. (1995). Benzoyl-coenzyme A reductase (dearomatizing), a key enzyme of anaerobic aromatic metabolism. ATP dependence of the reaction, purification and some properties of the enzyme from Thauera aromatica strain K172. Eur. J. Biochem. 234, 921-933.

Bork, P. \& Doolittle, R. F. (1994). Drosophila kelch motif is derived from a common enzyme fold. J. Mol. Biol. 236, 1277-1282.

Bork, P. \& Koonin, E. V. (1998). Predicting functions from protein sequences-where are the bottlenecks? Nature Genet. 18, 313-318.

Bork, P., Sander, C. \& Valencia, A. (1992). An ATPase domain common to prokaryotic cell cycle proteins, sugar kinases, actin, and hsp70 heat shock proteins. Proc. Natl Acad. Sci. USA, 89, 7290-7294.

Callebaut, I. \& Mornon, J. P. (1998). The V(D)J recombination activating protein RAG2 consists of a sixbladed properller and a PHD fingerlike domain, as revealed by sequence analysis. Cell Mol. Life Sci. 54, 880-891.

Cashel, M., Gentry, D. R., Hernandez, V. J. \& Binella, D. (1996). The stringent response. In Escherichia coli and Salmonella: Cellular and Molecular Biology (Neidhardt, F. C., III, R, C., Ingraham, J. L., Lin, E. C. C., Low, K. B., Magasanik, B., Reznikoff, W. S., Riley, M., Schaechter, M. \& Umbarger, H. E., eds), pp. 1458-1496, ASM Press, Washington, DC.

Chen, L., Glover, J. N., Hogan, P. G., Rao, A. \& Harrison, S. C. (1998). Structure of the DNA-binding domains from NFAT, Fos and Jun bound specifically to DNA. Nature, 392, 42-48.

Chothia, C. (1992). Proteins. One thousand families for the molecular biologist. Nature, 357, 543-544.

Colbeau, A., Elsen, S., Tomiyama, M., Zorin, N. A., Dimon, B. \& Vignais, P. M. (1998). Rhodobacter capsulatus HypF is involved in regulation of hydrogenase synthesis through the HupUV proteins. Eur. J. Biochem. 251, 65-71.

da Costa e Silva, O. (1994). CG-1, a parsley lightinduced DNA-binding protein. Plant Mol. Biol. 25, 921-924.

Doolittle, R. F. (1995). The origins and evolution of eukaryotic proteins. Phil. Trans. Roy. Soc. ser. B, 349, 235-240.

Esser, L., Wang, C. R., Hosaka, M., Smagula, C. S., Sudhof, T. C. \& Deisenhofer, J. (1998). Synapsin I is structurally similar to ATP-utilizing enzymes. EMBO J. 17, 977-984.

Fortini, M. E. \& Artavanis-Tsakonas, S. (1994). The suppressor of hairless protein participates in notch receptor signaling. Cell, 79, 273-282.

Galperin, M. Y. \& Koonin, E. V. (1997). A diverse superfamily of enzymes with ATP-dependent carboxylate-amine/thiol ligase activity. Protein Sci. 6, 26392643.

Gane, P. J., Dunwell, J. M. \& Warwicker, J. (1998). Modeling based on the structure of vicilins predicts a histidine cluster in the active site of oxalate oxidase. J. Mol. Evol. 46, 488-493.

Ghosh, G., van Duyne, G., Ghosh, S. \& Sigler, P. B. (1995). Structure of NF-kappa B p50 homodimer bound to a kappa B site. Nature, 373, 303-310.

Gibson, J., Dispensa, M. \& Harwood, C. S. (1997). 4-Hydroxybenzoyl coenzyme A reductase (dehydroxylating) is required for anaerobic degradation 
of 4-hydroxybenzoate by Rhodopseudomonas palustris and shares features with molybdenum-containing hydroxylases. J. Bacterial. 179, 634-642.

Gottesman, S. (1996). Proteases and their targets in Escherichia coli. Annu. Rev. Genet. 30, 465-506.

Gottesman, S. \& Maurizi, M. R. (1992). Regulation by proteolysis: energy-dependent proteases and their targets. Microbiol. Rev. 56, 592-621.

Grant, G. A., Schuller, D. J. \& Banaszak, L. J. (1996). A model for the regulation of D-3-phosphoglycerate dehydrogenase, a Vmax-type allosteric enzyme. Protein Sci. 5, 34-41.

Hagman, J., Gutch, M. J., Lin, H. \& Grosschedl, R. (1995). EBF contains a novel zinc coordination motif and multiple dimerization and transcriptional activation domains. EMBO J. 14, 2907-2916.

Henikoff, S. \& Henikoff, J. G. (1994). Position-based sequence weights. J. Mol. Biol. 243, 574-578.

Hofmann, B. E., Bender, H. \& Schulz, G. E. (1989). Three-dimensional structure of cyclodextrin glycosyltransferase from Bacillus circulans at $3.4 \AA$ resolution. J. Mol. Biol. 209, 793-800.

Holm, L. \& Sander, C. (1995). DNA polymerase $\beta$ belongs to an ancient nucleotidyltransferase superfamily. Trends Biochem. Sci. 20, 345-347.

Holm, L. \& Sander, C. (1996). Mapping the protein universe. Science, 273, 595-603.

Holm, L. \& Sander, C. (1997). New structure-novel fold? Structure, 5, 165-171.

Hubbard, T. J. P., Ailey, B., Brenner, S. E., Murzin, A. G. \& Chothia, C. (1999). SCOP: a structural classification of proteins database. Nucl. Acids Res. 27, 254256.

Huynen, M., Doerks, T., Eisenhaber, F., Orengo, C., Sunyaev, S., Yuan, Y. \& Bork, P. (1998). Homologybased fold predictions for Mycoplasma genitalium proteins. J. Mol. Biol. 280, 323-326.

Jabbouri, S., Relic, B., Hanin, M., Kamalaprija, P., Burger, U., Prome, D., Prome, J. C. \& Broughton, W. J. (1998). nolO and noeI (HsnIII) of Rhisobium sp. NFR234 are involved in 3-O-carbamoylation and 2-O-methylation of Nod factors. J. Biol. Chem. 273, 12047-12055.

Kannabiran, C., Zeng, X. \& Vales, L. D. (1997). The mammalian transcriptional repressor RBP (CGF1) regulates interleukin-6 gene expression. Mol. Cell Biol. 17, 1-9.

Kee, Y., Yoo, J. S., Hazuka, C. D., Peterson, K. E., Hus, S. C. \& Scheller, R. H. (1997). Subunit structure of the mammalian exocyst complex. Proc. Natl Acad. Sci. USA, 94, 14438-14443.

Komoszynski, M. \& Wojtczak, A. (1996). Apyrases (ATP disphosphohydrolases, EC 3.6.1.5): function and relationship to ATPases. Biochim. Biophys. Acta, 1310, 233-241.

Koonin, E. V. (1994). Yeast protein controlling interorganelle communication is related to bacterial phosphatases containing the Hsp70-type ATP-binding domain. Trends Biochem. Sic. 19, 156-157.

Lupas, A. (1996). Prediction and analysis of coiled-coil structures. Methods Enzymol. 266, 513-525.

Maestrini, E., Tamagnone, L., Longati, P., Cremona, O., Gulisano, M., Bione, S., Tamanini, F., Neel, B. G., Toniolo, D. \& Comoglio, P. M. (1996). A family of transmembrane proteins with homology to the MET-hepatocyte growth factor receptor. Proc Natl Acad. Sci. USA, 93, 674-678.

Martin, J. \& Hartl, F. U. (1997). Chaperone-assisted protein folding. Curr. Opin. Struct. Biol. 7, 41-52.
Mellors, A. \& Lo, R. Y. (1995). O-sialoglycoprotease from Pasteurella haemolytica. Methods Enzymol. 248, 728-740.

Muller, C. W., Rey, F. A., Sodeoka, M., Verdine, G. L. \& Harrison, S. C. (1995). Structure of the NF-kappa B p50 homodimer bound to DNA. Nature, 373, 311317.

Murzin, A. G. (1996). Structural classification of proteins: new superfamilies. Curr. Opin. Struct. Biol. 6, 386-394.

Murzin, A. G. (1998). How far divergent evolution goes in proteins. Curr. Opin. Struct. Biol. 8, 380-387.

Murzin, A. G. \& Bateman, A. (1997). Distant homology recognition using structural classification of proteins. Proteins: Struct. Funct. Genet. 1, 105-112.

Murzin, A. G., Brenner, S. E., Hubbard, T. \& Chothia, C. (1995). SCOP: a structural classification of proteins database for the investigation of sequences and structures. J. Mol. Biol. 247, 536-540.

Mushegian, A. R., Bassett, D. E., Jr, Boguski, M. S., Bork, P. \& Koonin, E. V. (1997). Positionally cloned human disease genes: patterns of evolutionary conservation and functional motifs. Proc. Natl Acad. Sci. USA, 94, 5831-5836.

Neuwald, A. F., Liu, J. S. \& Lawrence, C. E. (1995). Gibbs motif sampling: detection of bacterial outer membrane protein repeats. Protein Sci. 4, 1618-1632.

Oettinger, M. A. (1996). Cutting apart V(D)J recombination. Curr. Opin. Genet. Dev. 6, 141-145.

Orengo, C. A., Jones, D. T. \& Thornton, J. M. (1994). Protein superfamilies and domain superfolds. Nature, 372, 631-634.

Patte, J. C., Richaud, C., Boy, E., Reinisch, F., Richaud, F. \& Cassan, M. (1976). Regulation of lysine biosynthesis in Escherichia coli K12. Acta Microbiol. Acad. Sci. Hung. 23, 121-128.

Peitsch, M. C. (1996). ProMod and Swiss-Model: internet-based tools for automated comparative protein modelling. Biochem. Soc. Trans. 24, 274-279.

Pittard, J. (1996). The various strategies within the TyrR regulation of Escherichia coli to modulate gene expression. Genes Cells, 1, 717-725.

Prasad, B. C., Ye, B., Zackhary, R., Schrader, K., Seydoux, G. \& Reed, R. R. (1998). unc-3, a gene required for axonal guidance in Caenorhabditis elegans, encodes a member of the O/E family of transcription factors. Development, 125, 1561-1568.

Reizer, J., Reizer, A., Saier, M. H., Jr, Bork, P. \& Sander, C. (1993). Exopolyphosphate phosphatase and guanosine pentaphosphate phosphatase belong to the sugar kinse/actin/hsp 70 superfamily. Trends Biochem. Sci. 18, 247-248.

Rhee, S. G., Park, S. C. \& Koo, J. H. (1985). The role of adehylyltransferase and uridylyltransferase in the regulation of glutamine synthetase in Escherichia coli. Curr. Top. Cell Reg. 27, 221-232.

Rost, B. \& Sander, C. (1994). Combining evolutionary information and neural networks to predict protein secondary structure. Proteins: Struct. Funct. Genet. $19,55-72$

Rost, B., Casadio, R., Fariselli, P. \& Sander, C. (1995). Transmembrane helices predicted at $95 \%$ accuracy. Protein Sci. 4, 521-533.

Rychlewski, L., Zhang, B. \& Godzik, A. (1998). Fold and function predictions for Mycoplasma genitalium proteins. Fold. Design, 3, 229-238.

Satoda, M., Takagi, S., Ohta, K., Hirata, T. \& Fujisawa, H. (1995). Differential expression of two cell surface 
proteins, neuropilin and plexin, in Xenopus olfactory axon subclasses. J. Neurosci. 15, 942-955.

Schuler, G. D., Altschul, S. F. \& Lipman, D. J. (1991). A workbench for multiple alignment construction and analysis. Proteins: Struct. Funct. Genet. 9, 180190.

Schuller, D. J., Grant, G. A. \& Banaszak, L. J. (1995). The allosteric ligand site in the Vmax-type cooperative enzyme phosphoglycerate dehydrogenase. Nature Struct. Biol. 2, 69-76.

Schweisguth, F. (1995). Suppressor of Hairless is required for signal reception during lateral inhibition in the Drosophila pupa notum. Development, 121, 1875-1884.

Shirakata, Y., Shuman, J. D. \& Coligan, J. E. (1996). Purification of a novel MHC class I element binding activity from thymus nuclear extracts reveals that thymic RBP-Jkappa/CBF1 binds to NF-kappaB-like elements. J. Immunol. 156, 4672-4679.

Shuman, S. (1996). Closing the gap on DNA ligase. Structure, 4, 653-656.

Shuman, S. \& Schwer, B. (1995). RNA capping enzyme and DNA ligase: a superfamily of covalent nucleotidyl transferases. Mol. Microbiol. 17, 405-410.

Subramanya, H. S., Doherty, A. J., Ashford, S. R. \& Wigley, D. B. (1996). Crystal structure of an ATPdependent DNA ligase from bacteriophage T7. Cell, 85, 607-615.

Thompson, J. D., Higgins, D. G. \& Gibson, T. J. (1994). CLUSTAL W: improving the sensitivity of progressive multiple sequence alignment through sequence weighting, position-specific gap penalties and weight matrix choice. Nucl. Acids Res. 22, 4673-4680.

Vande Woude, G. F., Jeffers, M., Cortner, J., Alvord, G., Tsarfaty, I. \& Resau, J. (1997). Met-HGF/SF: tumorigenesis, invasion and metastasis. Ciba Found. Symp. 212, 119-130, 130-132, 148-154.

Van Gent, D. C., McBlane, J. F., Ramsden, D. A., Sadofsky, M. J., Hesse, J. E. \& Gellert, M. (1995). Initiation of $\mathrm{V}(\mathrm{D}) \mathrm{J}$ recombination in a cell-free system. Cell, 81, 925-934.

van Gent, D. C., Mizuuchi, K. \& Gellert, M. (1996). Similarities between initiation of $\mathrm{V}(\mathrm{D}) \mathrm{J}$ recombination and retroviral integration. Science, 271, 1592-1594.

Vingron, M. \& Sibbald, P. R. (1993). Weighting in sequence space: a comparison of methods in terms of generalized sequences. Proc. Natl Acad. Sci. USA, 90, 8777-8781.

Vyazmensky, M., Sella, C., Barak, Z. \& Chipman, D. M. (1996). Isolation and characterization of subunits of acetohydroxy acid synthase isozyme III and reconstitution of the holoenzyme. Biochemistry, 35, 1044910346.

Walker, D. R. \& Koonin, E. V. (1997). SEALS: a system for easy analysis of lots of sequences. Intell. Syst. Mol. Biol. (ISMB), 5, 333-339.

Wang, M. M. \& Reed, R. R. (1993). Molecular cloning of the olfactory neuronal transcription factor Olf- 1 by genetic selection in yeast. Nature, 364, 121-126.

Wang, T. F. \& Guidotti, G. (1998). Golgi localization and functional expression of human uridine diphosphatase. J. Biol. Chem. 273, 11392-11399.

Watanabe, K., Ishikawa, T., Mukohara, Y., Nakamura, H., Boll, M., Albracht, S. S. \& Fuchs, G. (1992). Cloning and sequencing of the genes involved in the conversion of 5-substituted hydantoins to the corresponding L-amino acids from the native plasmid of Pseudomonas sp. strain NS671. J. Bacteriol. 174, 962-969.

Wilson, T. J., Argaet, V. P., Howeltt, G. J. \& Davidson, B. E. (1995). Evidence for two aromatic amino acidbinding sites, one ATP-dependent and the other ATP-independent, in the Escherichia coli regulatory protein TyrR. Mol. Microbiol. 17, 483-492.

Wolf, Y. I., Brenner, S. E., Bash, P. A. \& Koonin, E. V. (1999). Distribution of protein folds in the three superkingdoms of life. Genome Res. 9, 17-26.

Wootton, J. C. (1994). Non-globular domains in protein sequences: automated segmentation using complexing measures. Comput. Chem. 18, 269-285.

Wootton, J. C. \& Federhen, S. (1996). Analysis of composiitonally biased regions in sequence databases. Methods Enzymol. 266, 554-571.

Ye, G. J., Breslow, E. B., Meister, A. \& Gjo-jie, G. E. (1996). The amino acid sequence of rat kidney 5-oxo-L-prolinase determined by cDNA cloning. J. Biol. Chem. 271, 32293-32300.

Zhang, S., Burkett, T. J., Yamashita, I. \& Garfinkel, D. J. (1997). Genetic redundancy between SPT23 and MGA2: regulators of Ty-induced mutations and Ty1 transcription in Saccharomyces cerevisiae. Mol. Cell Biol. 17, 4718-4729.

Edited by J. M. Thornton 